\title{
Vine copula ensemble downscaling for precipitation projection over the Loess Plateau based on high-resolution multi-RCM outputs
}

\author{
Chaoxing Sun', Guohe Huang ${ }^{2, *}$, Yurui Fan ${ }^{3}$, Xiong Zhou ${ }^{4}$, Chen $\mathrm{Lu}^{4}$, Xiuquan Wang ${ }^{5}$
}

1. Institute for Energy, Environment and Sustainability Research, UR-NCEPU, North China Electric Power University, Beijing 102206, China

2. Center for Energy, Environment and Ecology Research, UR-BNU, Beijing Normal University, Beijing 100875, China

3. College of Engineering, Design and Physical Sciences, Brunel University, London, Uxbridge, Middlesex, UB8 3PH, United Kingdom

4. Faculty of Engineering and Applied Science, University of Regina, Regina, SK, Canada, S4S0A2

5. School of Climate Change and Adaptation, University of Prince Edward Island, Charlottetown, Prince Edward Island C1A 4P3, Canada

*Corresponding Author: Guohe Huang (huang@iseis.org)

Center for Energy, Environment and Ecology Research, UR-BNU, Beijing Normal University, Beijing 100875, China. Tel: +13065854095; Fax: +13063373205

\section{Key points:}

- A vine copula ensemble downscaling method is proposed to jointly downscale the projected precipitation from multiple climate models.

- Post-simulation analyses of monthly precipitation projections over the Loess Plateau were conducted using seven regional climate models.

- This method can generate more ensemble series than conventional bias-correction methods, and thus more robust projections.

This article has been accepted for publication and undergone full peer review but has not been through the copyediting, typesetting, pagination and proofreading process, which may lead to differences between this version and the Version of Record. Please cite this article as doi: 10.1029/2020WR027698. 


\begin{abstract}
A vine copula ensemble downscaling (VCED) framework is proposed to jointly downscale the projected precipitation from multiple regional climate models (RCMs). This approach can effectively reduce the biases inherent to precipitation projections from different RCMs and thus provide more reliable ensemble projections. The proposed approach was applied to RCM projections over the Loess Plateau of China, which features complex topography and various climatic zones. Precipitation projections from 7 RCMs were used, and 21 sets of downscaling results were obtained. The performance of the VCED in reproducing historical precipitation across the Loess Plateau was evaluated using mean absolute error (MAE), the Taylor diagram, and the rank histogram (RH). The proposed VCED approach was found to be more effective than quantile mapping and bivariate copula methods in achieving robust precipitation projections. Overall flat RH diagrams indicate that the ensemble prediction and observations have strong consistency in distribution. Future precipitation changes of two 30-year periods (i.e., the 2050s and 2080s) under two Representative Concentration Pathway (RCP) scenarios (RCP 4.5 and RCP 8.5) over the Loess Plateau were then analyzed after post-downscaling processes. The results show that the average annual precipitation over the Loess Plateau may increase by 8.4 to $11.4 \%$ under the RCP 4.5 scenario and by 9.3 to $17.5 \%$ under RCP 8.5. The projected precipitation in the south-central parts of the Loess Plateau would be significantly reduced whereas those of the other parts be significantly increased.
\end{abstract}

\title{
1. Introduction
}

Climate change can profoundly affect the availability and viability of water resources. In order to predict possible future climate change and assess the associated impacts on water resources, global climate models (GCMs) are commonly used to generate climate projections under different Representative Concentration Pathway scenarios (RCPs; Johnson \& Sharma, 2011; Li et al., 2012; Wang et al., 2014). However, GCMs are often too coarse to accurately evaluate climate characteristics at regional and local scales. In view of this, downscaling techniques have been developed to transform coarse GCM outputs into high-resolution representations. Downscaling approaches can be divided into two categories. Statistical downscaling generates local-scale simulations by utilizing statistical relationships between observations and GCM outputs (Clark et al., 2004, Thober et al., 2013, Hou et al., 2019). Dynamical downscaling is an analytical process in which the outputs of GCMs are used as the initial boundary conditions that drive regional climate models (RCMs) to produce high-precision projections (Boé et al., 2007; Chen et al., 2013; Thober et al., 2014; Wang \& Chen, 2014; Zhou et al., 2018). RCMs can more specifically describe complex surface features and climatic processes in a particular region, and can also reproduce precipitation patterns more accurately than GCMs (Torma et al., 2015; Di Virgilio et al., 2019; Hou et al., 2019).

Much progress has been made in high-resolution climate projections through RCMs. However, dynamic downscaling based on RCMs still faces a number of challenges. For example, RCMs are sensitive to the level of resolution used, modeling schemes, and input parameters (Lee et al., 2007; Bowden et al., 2012; Hu et al., 2018). Given these challenges, RCM outputs may show significant deviations when regional climate is simulated, especially for precipitation in

This article is protected by copyright. All rights reserved. 
areas with variable topography; this is the case for the Loess Plateau which is dominated by hilly and gully areas (Frei, 2003; Laflamme et al., 2016; D'Oria et al., 2017). Only by demonstrating the credibility of RCMs in downscaling historical climate can we gain confidence in their prediction of future climate (Liang et al., 2006; Thober, et al., 2012; Harding \& Snyder, 2014; $\mathrm{Hu}$ et al., 2018). Consequently, RCM outputs that significantly deviate from observations should be further downscaled (or bias corrected) before being used to assess climate impacts (Themeß1 et al., 2011; Teutschbein, \& Seibert, 2012; Gudmundsson et al., 2012, Thober and Samaniego, 2014; IPCC, 2015). It is also crucial to recognize that such adjustment remains a controversial approach with its own pros and cons; adjusted simulations should be used carefully with a full understanding of the potential limitations associated with inherent statistical assumptions (CORDEX; IPCC, 2015). To deal with this issue, many post-processing approaches aimed at correcting biased climate model outputs have been developed in recent years (Boé et al., 2007; Engen-Skaugen, 2007; Piani et al., 2010a, 2010b; Johnson \& Sharma, 2011; Themeß1 et al., 2011; Dosio \& Paruolo, 2012; Chen et al., 2013; Zhou et al., 2018). These methods can be classified into two categories according to their complexity: simple methods(e.g. linear transformation) and sophisticated ones (e.g. quantile mapping, or Qmap; Piani et al., 2010a, 2010b); in the Qmap, biases are reduced through the establishment of statistical relationships between the cumulative density functions (CDFs) of observed variables and those of projected ones. Model outputs are always downscaled to station scales while reducing model error; thus, bias correction is also considered a downscaling process (Gudmundsson et al., 2012; Chen et al., 2013; D'Oria et al., 2017).

Due to their capacity in constructing joint dependence structure among different variables and the flexibility to select multiple functions, copula-related methods were developed for use in hydrological and climate studies (Nelsen, 2006; Serinaldi, 2009; Samaniego et al., 2010; Fan et al., 2015; Kong et al., 2015; Wei \& Liu, 2018). More recently, methods based on bivariate copulas (or Bi-Copula methods) were introduced to the field of bias correction in climate projections (Vogl et al., 2012; Mao et al., 2015; Zhou et al., 2018; Alidoost et al., 2019; Maity et al., 2019). For instance, Mao et al. (2015) and Zhou et al. (2018) have applied Bi-Copula method to correct precipitation projections from WRF (Weather Research and Forecasting Model) and temperature projections from PRECIS (Providing Regional Climates for Impacts Studies), respectively. Their results showed that, compared with Qmap, the Bi-Copula method is more robust in building statistical relationships between observations and simulations.

Post-downscaling methods (such as Qmap and Bi-Copula) face a number of general challenges. (i) They are based on individual RCM outputs, and reflect only one-to-one relationships between simulations (from each RCM output) and observations (e.g. PRECIS in Zhou et al. (2018), and WRF in Mao et al. (2015) and Maity et al. (2019)). (ii) Different RCMs perform unevenly when simulating regional climate, leading to great deviations especially in the case of precipitation in areas with complex terrains. One-to-one relationships (outputs from one RCM vs. observations) are unable to reflect these uncertainties (or abnormal deviations). (iii) Existing approaches generate deterministic results, without reflection the uncertainties that exist in modeling parameters and input conditions. To address the above challenges, a vine copulabased ensemble downscaling (VCED) method was developed, in which the vine copula

This article is protected by copyright. All rights reserved. 
(Brechmann \& Schepsmeier, 2013) was designed to reflect interdependence among information from observations and RCM projections, and probabilistic distributions were derived for downscaled variables conditional on projections from RCM models. The distributions obtained can provide bases for jointly downscaling RCM projections in both deterministic and probabilistic expressions.

The Loess Plateau in China was chosen as the study area. The proposed VCED model was established based on the probabilistic dependence between historical observations and the corresponding outputs from multiple RCMs. In detail, simulated precipitation for historical and projected future periods from seven RCMs over the Loess Plateau were used as inputs for the VCED framework. The vine copula method was used to build probability correlations between RCM projections and observations and export post-downscaled results based on this relationship. The jointly downscaled historical simulations obtained using the developed method were compared against observations to evaluate the performance of the VCED approach. The approach was then compared against Qmap and Bi-Copula methods to further assess its performance. Finally, future changes in precipitation over the Loess Plateau were estimated based on ensemble predictions.

\section{Study area and data}

\subsection{Study area}

The Loess Plateau (between $33^{\circ} 43^{\prime} \mathrm{N}$ to $41^{\circ} 16^{\prime} \mathrm{N}$ and $100^{\circ} 54^{\prime} \mathrm{E}$ to $114^{\circ} 33^{\prime} \mathrm{E}$ ), is located in the upper and central reaches of the Yellow River watershed in North China (Figure 1). The region covers an area of approximately $640,000 \mathrm{~km}^{2}$ and its total population is around 86 million. The majority of the region has a sub-humid and semiarid climate, with annual mean temperatures ranging from $4.3^{\circ} \mathrm{C}$ to $14.3^{\circ} \mathrm{C}$ and annual precipitation fluctuating from 150 to $800 \mathrm{~mm}$, increasing from the northwest to the southeast. $60-70 \%$ of the annual total rainfall occurs as high-intensity rainstorms between June and September (Liang et al., 2015). The average annual air temperature in the Loess Plateau has significantly increased over the past 60 years $\left(0.22{ }^{\circ} \mathrm{C}\right.$ per decade), while precipitation across the Loess Plateau has shown a slightly decreasing trend $\left(-1.2 \mathrm{~mm} \mathrm{yr}^{-1}\right)$ during the same period (Wang et al., 2017b). Although over $8.5 \%$ of the population of the country resides in the region, the water resources of the Loess Plateau account for only $2 \%$ of China's total water resources. The water utilization ratio of the major rivers is up to $70 \%$, far exceeding the internationally recognized threshold of $40 \%$ (Gao et al., 2009). Furthermore, according to the Yellow River Water Resources Bulletin, rapid development of the social economy has led to human water consumption increasing by $86 \%$ over the Loess Plateau from the 1980s to 2010 (Gao et al., 2017; Wang et al., 2017b).

Place for Figure 1

This article is protected by copyright. All rights reserved. 
The Loess Plateau was chosen as the research area for two main reasons. Firstly, there is a need for practical research in the region. As a large ecological and agricultural zone in China, the natural conditions of the Loess Plateau (i.e., water shortages, severe soil erosion, and unique landscape, etc.) make it crucial to study the climate change characteristics in this area (Zhang et al., 2012). However, due to the complex characteristics of the region, simulation results are often of low reliability, and few related studies have been conducted over the entirety of the Loess Plateau (Li et al., 2012; Liu \& Tang, 2013; Wang et al., 2017a). Secondly, the study area can satisfy the applicability test of the proposed method. With complex topography (altitude ranging from 800 to $3000 \mathrm{~m}$ ), diverse climatic types, and an uneven distribution of precipitation, the RCMs generally have difficulties in robustly capturing spatial and temporal variabilities of precipitation over the region (Wang et al., 2017a); consequently, deviations may exist between simulations and observations. Therefore, applicability of the developed method in refining climate projections can be fully tested over the Loess Plateau.

\subsection{Data}

Due to uncertainties in modeling parameters and input conditions, projection results from different RCMs tend to be very different and multi-RCMs are commonly used for ensemble projection in order to improve reliability (Buytaert et al., 2010; Deser, et al., 2012; D'Oria et al., 2017). Herein, the proposed VCED approach was applied to integrate outputs from multiple RCMs to provide deterministic and probabilistic climate projections. In addition, a large group of RCM ensemble combinations were applied to enable complete verification of the applicability of the VCED model. Monthly precipitation projections (transformed from the daily scale) from seven RCMs with a horizontal resolution of $0.44^{\circ}$ across the Loess Plateau were used in this study for the following periods: historical (1986-2004), and the RCP4.5 and RCP8.5 scenarios (2036-2095) (Table 1). Three datasets were simulated by our research team, including datasets downscaled from HadGEM-ES through PRECIS

(www.metoffice.com/research/hadleycentre/models/PRECIS.html) and RegCM (Pal et al., 2007), and those downscaled from GFDL-ESM2M through the RegCM model. Four other RCM datasets were obtained from the Coordinated Regional Downscaling Experiment (CORDEX, Giorgi et al., 2009; http://www.cordex.org). The data of all RCMs were split into three periods: 1986-2004 (the baseline period), 2036-2065 (2050s), and 2066-2095 (2080s). Detailed information for data generation agencies and their RCMs and GCMs are shown in Table 1. The seven RCMs were numbered to facilitate subsequent analyses.

\section{Place for Table 1}

Observed monthly precipitation data for 44 meteorological stations across the Loess Plateau for the period between 1986 and 2015 (Figure 1, Table S1) were obtained from the China Meteorological Administration (http://cdc.cma.gov.cn). Data for the period of 1986 to 2004 were used for post-downscaling and validation analyses. The first 10-year data (1986-1995) were used to develop a joint downscaling model, whereas the remaining 9-year data (1996-2004) were used

This article is protected by copyright. All rights reserved. 
for validation. Data for the entire time period (1986 to 2015) were utilized for comparative study between historical and future periods.

\section{Methodology}

A single regional climate model is likely to be inadequate for simulating precipitation. In this case, the bias corrections for the outputs of a single RCM cannot capture realistic precipitation conditions. Therefore, combinations of multiple RCM outputs are used to jointly improve the reliability of simulations. This requires a method that can help establish statistical relationships among multiple RCM outputs, as well as observation records, such that improved robustness of precipitation projections can be accomplished. For this purpose, in the VCED model, the vine copula is used to construct a joint multivariate probability distribution based on the abundant dependency information of various bivariate copulas. The projected precipitation can thus be refined by using the established statistical relationships among the observations and outputs from every two of the seven RCMs. Developed by Sklar (1959), copulas are functions that connect univariate distribution functions to form multivariate distribution functions. A joint distribution function $F$ for a random vector with $n$ components can be expressed as:

$$
F\left(x_{1}, x_{2}, \ldots, x_{n}\right)=C\left(F_{1}\left(x_{1}\right), F_{2}\left(x_{2}\right), \ldots, F_{n}\left(x_{n}\right)\right)
$$

where $C$ is the copula function corresponding to $F$, and $F_{l}\left(x_{1}\right), F_{2}\left(x_{2}\right), \ldots, F_{n}\left(x_{n}\right)$ are marginal distributions of the random vectors $\left(\boldsymbol{X}_{1}, \boldsymbol{X}_{2}, \ldots, \boldsymbol{X}_{n}\right)$. It is difficult to calculate the joint distribution of multiple variables directly. The core function of the vine copula is to perform an alternative decomposition of a multivariate density into a set of bivariate copula densities related to the original variables and their conditional variables (Aas et al., 2006). The basic theory and application of vine copulas can be found in Kurowicka and Joe (2011), and Brechmann \& Schepsmeier (2013). Details of the calculation process for new projections derived from the multivariate joint probability distribution (random vector with $\mathrm{n}$ components) can be found in Text S1.

In three-dimensional situations, a possible decomposition of the three-dimensional probability density function $f\left(x_{1}, x_{2}, x_{3}\right)$ can be written as:

$$
f\left(x_{1}, x_{2}, x_{3}\right)=f_{1}\left(x_{1}\right) f\left(x_{2} \mid x_{1}\right) f\left(x_{3} \mid x_{1}, x_{2}\right)
$$

According to Sklar's theorem, the conditional densities an then be expressed as:

$$
f\left(x_{2} \mid x_{1}\right)=\frac{f\left(x_{1}, x_{2}\right)}{f\left(x_{1}\right)}=f_{2}\left(x_{2}\right) c_{1,2}\left(F_{1}\left(x_{1}\right), F_{2}\left(x_{2}\right)\right)
$$

and

This article is protected by copyright. All rights reserved. 


$$
\begin{aligned}
f\left(x_{3} \mid x_{1}, x_{2}\right) & =\frac{f\left(x_{2}, x_{3} \mid x_{1}\right)}{f\left(x_{2} \mid x_{1}\right)}=\frac{f\left(x_{2} \mid x_{1}\right) f\left(x_{3} \mid x_{1}\right) c_{2,3 \mid 1}\left(F\left(x_{2} \mid x_{1}\right), F\left(x_{3} \mid x_{1}\right)\right)}{f\left(x_{2} \mid x_{1}\right)} \\
& =f\left(x_{3} \mid x_{1}\right) c_{2,3 \mid 1}\left(F\left(x_{2} \mid x_{1}\right), F\left(x_{3} \mid x_{1}\right)\right) \\
& =f\left(x_{3}\right) c_{1,3}\left(F_{1}\left(x_{1}\right), F_{3}\left(x_{3}\right)\right) c_{2,3 \mid 1}\left(F\left(x_{2} \mid x_{1}\right), F\left(x_{3} \mid x_{1}\right)\right)
\end{aligned}
$$

The joint density expressed by equation (2) is converted to a product of marginal distributions and bivariate copula densities $c_{1,2}, c_{1,3}$ and $c_{2,3 \mid 1}$. To determine the parameters for decomposed bivariate copula functions, the VCED requires marginal distributions fitted to RCM outputs and observations at each station. In this study, all marginal distributions were constructed using the Kernel estimation method, after which the Kolmogorov-Smirnov (K-S) test was employed to evaluate their performance (Zhou et al., 2018). Several commonly used copula functions were examined, including the Gaussian, Student's t, Clayton, Gumbel, and Frank copulas. The basic properties of the identified copula functions are presented in Table S2. Copula parameters can be estimated using the maximum likelihood method (MLE; Shih \& Louis, 1995). To ensure the accuracy of dependence structures in the VCED, the root-mean-square error (RMSE), Akaike information criterion (AIC), and Cramér von Mises statistic (Genest et al., 2009) were used to perform goodness-of-fit tests for the copulas (Fan et al., 2015). A copula with a minimum AIC or RMSE (or combination of both) was considered the most appropriate. The performance of the chosen copula was then further tested using the $p$-value of the Cramér von Mises statistic.

In the calculation for joint density of multiple variables (e.g. Equation 2), the potential schemes with combinations of climatic variables are diverse, and thus multiple dependence structures can be established. Figure 2 shows a vine copula structure corresponding to formulas (2) to (4). Figure 2(a) depicts the vine copula structure of two trees with three edges (each edge is associated with a pair-copula). Variables 1 and 2 ( $x_{1}$ and $x_{2}$ in formulas (2) to (4)) in each structure tree represent precipitation projections from two RCMs, whereas variable 3 ( $x_{3}$ in formulas (2) to (4)) represents the corresponding observations. According to the structure tree in Figure 2(a), a three-layer marginal distribution and three bivariate copula functions can be established (Figure 2(b)). Using the probability integral transform (Rosenblatt, 1952; see also Text S1), new projections can thus be generated.

Place for Figure 2

To illustrate the usage of this method more intuitively, a simple example with variables of $x_{1}, x_{2}$, and $x_{3}$ and the corresponding CDFs of $\boldsymbol{u}_{1}, \boldsymbol{u}_{2}$, and $\boldsymbol{u}_{3}$ (with a sample size of 1,000 for $\boldsymbol{u}_{1}$, $\boldsymbol{u}_{2}$, and $\left.\boldsymbol{u}_{3}\right)$ is presented. The Frank copula is fitted to each pair of decomposed variables, with the sample size of $\boldsymbol{u}_{1}, \boldsymbol{u}_{2}$, and $\boldsymbol{u}_{3}$ each being 1,000. Kendall's $\tau$ values between the pair-variables (i.e. $x_{1} \sim x_{2}, x_{1} \sim x_{3}$ and $\left.x_{2}\left|x_{1} \sim x_{3}\right| x_{1}\right)$ and corresponding Frank copula parameters $\theta_{1}, \theta_{2}, \theta_{3}$ are displayed in Figure 2(a).

This article is protected by copyright. All rights reserved. 
In the case where the data for $\boldsymbol{u}_{1}, \boldsymbol{u}_{2}$, and $\boldsymbol{u}_{3}$ are known (at the model training phase), a set of dependent variables $\boldsymbol{u}_{1}, \boldsymbol{u}_{2}, \boldsymbol{u}_{3}$ is converted into a set of independent and uniform variables on the $[0,1]$ interval $\left(\boldsymbol{w}_{1}, \boldsymbol{w}_{2}, \boldsymbol{w}_{3}\right)$ according to the probability integral transform (Equations 7 and 8 in Text S1). Figure 3 shows the Rosenblatt transform and its inverse calculation results (Eq. (7) and Eq. (8) in Text S1). Figure 3(a) shows the correlation between the original $\boldsymbol{u}_{2}$ and $\boldsymbol{u}_{3}$. Figure $3(\mathrm{~b})$ indicates a lack of correlation between $\boldsymbol{w}_{2}$ and $\boldsymbol{w}_{3}$ (independent) after transformation calculation, where $\boldsymbol{w}_{2}=C_{2 \mid 1}\left(\boldsymbol{u}_{\mathbf{2}} \mid \boldsymbol{u}_{1}\right)$ and $\boldsymbol{w}_{\mathbf{3}}=C_{3 \mid, 2}\left(\boldsymbol{u}_{3} \mid \boldsymbol{u}_{1,2}\right)$. When $\boldsymbol{u}_{1}$ and $\boldsymbol{u}_{2}$ are known and $\boldsymbol{u}_{3}$ is unknown (at the validation and projection stages), the values of $\boldsymbol{u}_{3}$ can be estimated via the inverse Rosenblatt transform based on information from decomposed pair-copulas. Assume that one set of $\boldsymbol{u}_{\boldsymbol{1}}$ and $\boldsymbol{u}_{\mathbf{2}}$ (denoted as $u_{1, i}$ and $u_{2, i}$ ) is chosen from the 1,000 samples. In order to obtain the projections of $u_{3, i}, 300$ samples of $w_{3, i}$, which are uniformly distributed within [0,1], are generated through a Monte Carlo simulation (Zhou et al., 2018). Following this, a series of simulated $u_{3, i}$ values are obtained using the inverse Rosenblatt transform, and denoted as

$u_{3, i}=C_{3 \mid, 2}^{-1}\left(w_{3, i} \mid u_{1, i}, u_{2, i}\right)$. Figure 3 (c) shows the probability density distribution of 300 sampling results of $w_{3, i}$, and Figure $3(\mathrm{~d})$ shows the probability density distribution of the estimated $u_{3, i}$ (300 prediction values for $u_{3, i}$ ) conditional on $u_{1, i}$ and $u_{2, i}$. Simulation results for the entire $\boldsymbol{u}_{3}$ (averaged $u_{3, i}$ ) sequence are shown in Figure 3(e). Values of $x_{3}$ corresponding to simulation values of $\boldsymbol{u}_{3}$ can then be obtained.

Place for Figure 3

Detailed steps of the VCED model application used for downscaling the RCMs in this study can be generalized as follows. 1) Estimate the marginal distributions of $F_{1}\left(x_{1}\right), F_{2}\left(x_{2}\right)$, and $F_{3}\left(x_{3}\right)$ for precipitation of two RCM simulations and observations from the training period (1986-1995). 2) Estimate the parameters of decomposed pair-copulas related to the original variables and their conditional variables, then perform goodness-of-fit tests to select optimal copula functions. 3) Generate the $\boldsymbol{u}_{3}$ sequence for the training period according to the inverse probability integral transform. 4) Identify the interval around the maximum probability density value of simulated $\boldsymbol{u}_{3}$, with the mean value (mean of conditional CDF values) representing the final simulated value. 5) Generate the $\boldsymbol{u}_{3}$ sequence for the validation period (1996-2004) and verify the simulated $x_{3}$ values by comparing with the observations. 6) Project the changes of future precipitation relative to the baseline period base onto the validated model.

\section{Analysis of Results}

\subsection{Implementation and performance of the proposed approach}

In this study, joint downscaling was conducted using the proposed VCED model for every combination of two RCMs and was applied to each station. The VCED approach may be compared to the more commonly used technique of Qmap and newly developed Bi-Copula methods. The marginal distributions in the Bi-Copula method are consistent with those of the

This article is protected by copyright. All rights reserved. 
VCED approach, such that the relevant effects on the modeling results are insignificant. Data for 1986-1995 were used for calibrating the VCED model, while those for 1996-2004 were used for its validation. Twenty-one combinations of seven RCMs were introduced into the established VCED, resulting in 21 sets of jointly bias-corrected outputs. These schemes and their corresponding serial numbers (RCMs) are shown in Table 2.

Place for Table 2

Before making a comprehensive evaluation of the VCED model performance for all stations under each combination scheme, nine stations from scheme 1 (outputs from PRECIS and RegCM driven by HadGEM-ES) were selected to enable more detailed description and intuitive evaluation. The performance of PRECIS and RegCM outputs (monthly mean precipitation) during the validation period (1996-2004) for nine stations before post-downscaling processing is shown in Figure 4. These nine stations were chosen because they contain diverse comprehensive characteristics: 1) precipitation can be accurately simulated by both RCM models, i.e., RCM simulations are close to observations (e.g. Figure 4-3); 2) the outputs from only one model are close to observation values (Figure 4-1 and 4-7); and 3) both RCM outputs deviate significantly from the observed values. The simulation results of two RCMs at the same station are very different from each other and generally different from observations. The proposed method can therefore be tested through comparison with the calibration results from different methods under different simulation scenarios.

\section{Place for Figure 4}

A comparison of results using the VCED, Qmap, and Bi-Copula (monthly mean precipitation from schemes of PRECIS \& RegCM) methods at nine meteorological stations is shown in Figure 5. Figures 4 and 5 show that the Qmap and Bi-Copula methods largely fail to capture precipitation information accurately when the RCM outputs exhibit significant discrepancies. This implies that the VCED method has an improved capacity for identifying significant information in discrepant RCM outputs, such that more robust projections are achieved. In addition, the prediction interval, rather than fixed values, can be generated based on multiple sampling calculations (see Text S2, Figure S1 and Figure S2 in the appendix), which can be used for uncertainty analysis further to deterministic analyses.

Place for Figure 5

This article is protected by copyright. All rights reserved. 
The mean absolute error (MAE) of monthly mean precipitation (Figure 5) at each of the nine stations is shown in Table 3. This shows that the MAE values using Bi-Copula-PRECIS schemes are lower (2.87 mm lower on average) at all stations than those using the Qmap method, but higher (3.95 mm higher on average) than those from VCED. Similarly, most of the MAE levels from VCED are significantly lower than those from the Bi-Copula and Qmap RegCMs. The average MAE from VCED is 3.05 and $1.24 \mathrm{~mm}$ lower than that arising from the Bi-Copula and Qmap RegCMs, respectively. Thus, we can conclude from the MAE tests that: (i) the BiCopula method performs better than Qmap in bias-correcting precipitation projections, which is consistent with the conclusions of Zhou et al. (2018); and (ii) the proposed VCED based on multiple RCMs can produce better results than the Qmap and Bi-Copula methods.

Place for Table 3

The analyses detailed above show rough comparisons between post-downscaled and observed monthly mean precipitation for selected stations during the validation period. In order to verify the results for different quantile segments of precipitation series over all stations, the MAE was also used as a global quantitative evaluation method (Gudmundsson et al., 2012). A set of MAEs (MAE0.1, MAE0.2,...,MAE1.0) obtained from the equally-spaced probability intervals of empirical CDF (for observed information) were used to approximate the distributions of precipitation within different probability intervals. Figure 6(a) shows the mean precipitation over all stations for each month, denoting differences between simulated results from different methods and observations throughout the entire region. The results from VCED are closer to observational values than those from the Qmap and Bi-Copula methods, especially during the rainy season (June-August). Both the average MAE and the value of MAE at each probability interval (MAE $\mathrm{MA}_{0.1}, \mathrm{MAE}_{0.2}, \ldots, \mathrm{MAE}_{1.0}$ ) are shown in Figure 6(b). For specific probability intervals, MAE values from VCED are generally lower than those using the Qmap and BiCopula methods (except $\mathrm{MAE}_{0.7}$ ). In detail, the $\mathrm{MAE}_{1.0}$ arising from VCED simulations (i.e. $24.52 \mathrm{~mm}$ ) is smaller than that arising from both the Qmap (35.81 mm for PRECIS and 37.79 $\mathrm{mm}$ for RegCM) and Bi-Copula methods (36.18 mm for PRECIS and $36.07 \mathrm{~mm}$ for RegCM). Detailed data from all MAEs used in Figure 6(b) and other schemes are shown in Table S3. These results demonstrate that VCED is advantageous for post-downscaling precipitation relative the existing Qmap and Bi-Copula methods, especially for individual wet months (or the rainy season).

Place for Figure 6

MAE values were calculated as the average of all stations after sorting precipitation values in ascending order. Taylor diagram verification was undertaken in order to evaluate the post-downscaled precipitation as time series. Figure 7 presents Taylor diagrams of correlation,

This article is protected by copyright. All rights reserved. 
root-mean-square (RMS) difference, and the ratio of standard deviation between simulations and observations (Taylor, 2001). In detail, seven RCM outputs led to 35 downscaling schemes comprising seven Qmap, seven Bi-Copula and 21 (i.e. C(7, 2)) VCED schemes. Figure 7(a) shows the mean correlation coefficient (MR), normalized standard deviation, and RMS differences between observations and simulations for each scheme at 44 stations (each point represents a station). The MRs of the tested Qmap schemes range from 0.461 to 0.580 , with an average of 0.518, while those of the tested Bi-Copula schemes range from 0.523 to 0.618 , with an average of 0.566 . In comparison, the proposed VCED schemes have MRs of 0.553 to 0.638 , with an average of 0.593 . The points corresponding to the VCED schemes are more concentrated to the unit radius (i.e., their ratio of variance is closer to 1). The closer the point to the horizontal axis, the lower the RMS difference between observations and simulations. Figure 7(b) shows the location of the mean distances of all points to the unit circle under each scheme, where the enlarged drawing marks the scheme numbers and corresponding points for each method. The average rates of deviation from the unit circle for the Qmap, Bi-Copula, and VCED methods were $23.4 \%, 18.5 \%$, and $15.3 \%$, respectively. In addition, the resulting 35 schemes were ranked according to the skill scores of statistical indicators (Figure 7(c); Taylor, 2001). The resulting score-based ordination diagram (Figure 7(c)) demonstrated that VCED schemes had a higher ranking than either the Qmap or Bi-Copula methods.

Place for Figure 7

The above validation methods may be used to verify the performance of each group of post-downscaling simulations. In addition, rank histograms (RH) were used (Anderson, 1996; Hamill, 2001) to evaluate the distribution reliability of ensemble projections. As a visual tool for assessing whether projections and observations have the same distribution, a flat RH is expected to indicate a satisfactory correlation. Figure 8 provides the RH validation results of VCED projections at all stations for 1996-2004. Most RHs are flat, indicating that the ensemble projections are credible. Several stations show a slight U-shape, indicating that the distribution of the projection results at these stations is slightly more concentrated. For the Wutai Mountain Station (station 15), at which many observations were outside of the ensemble extremes, the maximum probability is 0.10 higher than the mean line. This could arise from the fact that this station was moved from $2894 \mathrm{~m}$ to $2485 \mathrm{~m}$ above sea level in 1998, such that significant differences in surface conditions led to discrepancies in the observation data.

Place for Figure 8

Figure 9 shows the ensemble projected intervals of monthly mean precipitation at the 44 stations based on 21 post-downscaling groups using the VCED model at the verification stage (1996-2004). The average deviation between the groups of prediction results and observations

This article is protected by copyright. All rights reserved. 
ranges from $3.5 \mathrm{~mm}$ to $12.1 \mathrm{~mm}$. The ensemble intervals at some stations are slightly larger, however, all ensemble mean predictions are close to observational values, confirming their validity.

\section{Place for Figure 9}

\subsection{Projections of future precipitation changes}

To better understand future precipitation changes across the Loess Plateau, the ensemble projections of future precipitation under two RCP scenarios (i.e., RCP4.5 and RCP8.5) for two 30-year periods (i.e., the 2050s and 2080s) were generated using the VCED model. Precipitation projections for future scenarios were then compared with historical observations (1986-2015).

Figure 10 presents a comparison of average annual total precipitation between historical observations and the mean ensemble projections of two future 30-year periods under two RCP scenarios. The interpolation figure obtained by Kriging shows that the spatial distributions of average annual precipitation under future scenarios are similar to those known throughout historical records (i.e., increasing from the northwest to the southeast). In general, projected future precipitation values in most areas of the Loess Plateau are higher than the corresponding values from historical observations, especially in the western region. The average annual total precipitation over the entire Loess Plateau increases by $8.4 \%$ and $11.4 \%$ for the 2050 s and 2080s, respectively, under the RCP 4.5 scenario. In comparison, the average annual total precipitation increases by $9.3 \%$ and $17.5 \%$ for the 2050 s and $2080 \mathrm{~s}$, respectively, under the RCP 8.5 scenario. Variations in the projected precipitation of different regions are inconsistent, ranging from $-23.4 \mathrm{~mm}$ to $110.8 \mathrm{~mm}$ for RCP 4.5 and from $-19.2 \mathrm{~mm}$ to $133.3 \mathrm{~mm}$ for RCP 8.5. Based on the ensemble projections, these uncertain intervals of future precipitation were determined to reveal the extreme situations possible for future precipitation. The upper and lower limits of average annual total precipitation under both RCP scenarios are compared to historical observations in Figures S3 and S4). The monthly mean precipitation changes for each station under the RCP scenarios for the 2050s and 2080s relative to historical conditions are shown in Figure S5 to S8.

\section{Place for Figure 10}

Annual precipitation across the Loess Plateau is expected to increase significantly based on the ensemble predictions. However, as the region with the most serious soil erosion, it is necessary to study future precipitation changes in the rainy season (July-September) since this accounts for $57.2 \%$ (historical) of the annual total precipitation in this region. Figure 11 compares the mean precipitation in the rainy season from the historical period against the two 30 -year future periods considered. Figure 11(a) is an interpolation map of precipitation in the

This article is protected by copyright. All rights reserved. 
historical rainy season. Rows 2 to 4 show the means, and the lower and upper bounds, of the ensemble predictions for the future rainy season, respectively. The simulated precipitation along the spatial trend in all future scenarios is largely consistent with that of the historical record. The upper and lower bounds of projections show extreme cases of ensemble predictions, whereas the mean ensemble predictions are general cases with relatively high probabilities of occurrence.

The mean ensemble simulations show that the projected precipitation in the south-central part of the Loess Plateau is significantly reduced under both future scenarios, contrary to the precipitation changes predicted in other regions. Under this circumstance, the difference between the precipitation in the northern and southern regions would be significantly reduced.

\section{Place for Figure 11}

According to these results, precipitation during future rainy seasons on the Loess Plateau may have obvious spatial and temporal changes in distribution relative to the present. Figure 12 shows the changes of mean ensemble precipitation in the rainy season under two RCP scenarios relative to the historical period. The precipitation variation interval at different stations and in different periods under the two tested RCP scenarios ranges from -50.5 to $71.8 \mathrm{~mm}$, which is significantly different from that of annual precipitation $(-23.4$ to $133.3 \mathrm{~mm})$. Projected precipitation changes are somewhat higher under RCP 8.5 than under RCP4.5. Rainy season precipitation in the northeast (stations in blue panels) would respectively increase by 25.9 and $25.0 \mathrm{~mm}$ in the 2050s and 2080s under RCP 4.5, and by 28.0 and $40.7 \mathrm{~mm}$ in the $2050 \mathrm{~s}$ and 2080s under RCP 8.5. In comparison, the precipitation in the rainy season in the south (stations in red panels) would respectively decrease by 34.8 and $3.8 \mathrm{~mm}$ during the $2050 \mathrm{~s}$ and $2080 \mathrm{~s}$ under RCP 4.5, and by $10.8 \mathrm{~mm}$ in the 2050s under RCP 8.5; however, RCP 8.5 results in an increased precipitation of $9.4 \mathrm{~mm}$ in the 2080s. Significant decreases and increases in precipitation occur in different regions during the rainy season, indicating that both the spatial and temporal distributions of precipitation may change significantly in the future.

\section{Place for Figure 12}

\section{Discussion}

In this study, a vine copula-based ensemble downscaling approach (VCED) was developed to jointly downscale monthly-precipitation projections from multiple RCMs. Similar to other downscaling methods, this approach assumes that the dependence structure among observed and projected precipitation amounts is stable during the study period (Mao et al., 2015). However, the essence of VCED is to generate downscaled/bias-corrected precipitation projections from multiple RCMs rather than from single models, and thus fully capitalize the information from discrepant RCM outputs. Moreover, VCED is able to produce multiple sets of

This article is protected by copyright. All rights reserved. 
projection series by pairing several climate models (e.g. seven RCMs have generated 21 sets of downscaed results in this study). These results can help improve the robustness in reflecting uncertainties in climate projections (Tebaldi \& Knutti, 2007).

In the VCED method, nonlinear dependencies in precipitation amounts from RCMs and observations can be captured through vine copulas, such that the conditional distributions of the precipitation (to be corrected) can then be derived. Such conditional distributions can facilitate bias-corrections for future projections based on their mean values (mean conditional CDF values, or mean CCVs). Therefore, an important issue of VECD is the robustness of conditional CDFs. The parameters in VCED are linked to the levels of correlations between RCM outputs and observed records, while these correlations may have significant impacts on the conditional CDFs. A proximity ratio (PR) was investigated at nine selected stations (Section 4.1) to illustrate such impacts (see Table S4 for the details of Kendall coefficients of correlation between precipitation levels from four RCMs and observed ones at each station). The $\operatorname{PR}(x, y)$ is the ratio of the mean CCVs that are more proximate to the corresponding CDF values from RCM_x than those from RCM $\_y$ (see Text S3 for detailed explanation of the PR calculation).

The results indicate that, the precipitation outputs from different RCMs would show different levels of correlation with the observations, leading to different Kendall coefficients. Moreover, when the differences among the obtained Kendall coefficients are significant (e.g. greater than 0.1), the resulting mean CCVs would have low likelihood of approaching the CDF values of those RCM simulations that have low Kendall coefficients (Table S5). For example, for $\mathrm{PR}(1,2)$, the correlation coefficients between RCM_1 outputs and observed records are significantly lower than those between RCM_2 outputs and observed records at Stations 2, 8, and 9 (Table S4). Consequently, the PR values at these three stations are significantly lower than $50 \%$, i.e., most of mean CCVs are close to CDF values from RCM_2 simulations. Among these stations, the difference of correlation coefficients at station 8 is the highest $(0.16)$, with less than $20 \%$ of mean CCVs being close to CDF values from RCM_1 simulations. These results indicate that, for the two RCMs with their outputs having different levels of correlation with the observations, the one with higher correlation would have a greater contribution to VCED. However, if the difference of correlation between the two RCMs is insignificant, then the other factors (e.g. types of marginal distributions or copula functions) would dominate the performance of VCED.

Another important factor affecting the conditional distributions is the type of dependence model. All marginal distributions of simulations and observations were constructed through Kernel estimations to mitigate the influence in terms of the choice of marginal distributions. Five copulas (i.e., Gaussian, Student's t, Clayton, Gumbel, and Frank copulas) were provided to express the dependence among simulations and observations; decomposed bivariate copulas were identified based on goodness-of-fit tests. However, different copulas might lead to different mean CCVs. The influence of copula function on conditional CDFs was investigated through comparisons of PR values from Frank and Gaussian copula schemes at nine stations, which mean that the bivariate dependence structures of VCED could be quantified through Frank or Gaussian copula (Table S6). The results demonstrate that, when the difference in correlation coefficients is

This article is protected by copyright. All rights reserved. 
greater than or equal to 0.02 , the mean CCVs from Frank copula scheme would have high likelihood of approaching the CDF values of those RCM outputs that have higher correlation with observations. In comparison, similar results can be obtained through Gaussian copula when the difference in correlation coefficients is greater than 0.06. Thus, Frank copula is more sensitive to the differences in correlation, and would produce higher PR values.

The MAE values for different probability intervals from Frank, Gaussian, and combined copula schemes at nine stations are also analyzed (Table S7). The combined copula scheme consists of decomposed bivariate copulas identified from the five options based on goodness-offit tests. The results indicate that the average MAEs from Frank copula are lower than those from Gaussian and combined ones. The MAE values from Frank copula at probability intervals of 0.7 to 1.0 are generally lower than those from combined ones. Although the results of $\mathrm{MAE}_{1.0}$ from Gaussian copula scheme are more accurate (the average $\mathrm{MAE}_{1.0}$ of six RCM combinations is $17.27 \mathrm{~mm}$ ), the mean values of $\mathrm{MAE}_{0.7}$ and $\mathrm{MAE}_{0.8}$ for six RCM combinations under this scheme are respectively 3.56 and $4.04 \mathrm{~mm}$ larger than those under copula combinations. Thus, Gaussian copula is less effective in reflecting the differences among high precipitation levels. In general, Frank copula is more sensitive to differences in correlation coefficients, and performs better in MAE analyses.

\section{Conclusions}

In this study, a VCED method has been developed to reflect interdependence among RCM simulations and observations, derive probabilistic distributions for downscaled variables conditional on RCM outputs, and jointly downscale RCM projections in both deterministic and probabilistic expressions. The proposed VCED has the following advantages: (i) information from multiple RCMs and a large number of ensemble bias-correction series can be generated to reflect the effects of multiple uncertainties (e.g. 7 RCMs, and 21 sets of downscaled results); (ii) for two RCMs with their outputs having significant difference in correlation with the observations, the one with poor correlation could hardly contribute significantly to the VCED; thus improved reliability in climate projections can be accomplished based on the improved robustness in reflecting such correlation differences.

The proposed VCED approach successfully facilitated the joint downscaling of projections from seven RCMs over the Loess Plateau, China for two 30-year periods under two RCP scenarios. The performance of VCED was demonstrated through comparisons with those of Qmap and Bi-Copula methods (MAE and Taylor diagrams). The MAE assessment results revealed that VCED is advantageous for the post-downscaling of precipitation, especially in wet months. The Taylor diagram verification results showed that the post-downscaled precipitation from VCED outperformed those from the two other methods in terms of correlation level, RMS difference, and the standard deviation. The results demonstrated that VCED is more effective in both identifying significant information from discrepant RCM outputs and achieving robust projections.

Based on the VCED results, variations in precipitation over the Loess Plateau were analyzed for two 30-year periods (2050s and 2080s) under two RCP scenarios (RCP 4.5 and

This article is protected by copyright. All rights reserved. 
RCP 8.5). It was found that such variations were inconsistent at different stations, regions and periods. Significant decreases or increases in precipitation during rainy seasons might occur at each temporal or spatial unit under both RCP scenarios. The projected precipitation in the southcentral Loess Plateau would significantly decrease during both 2050s and 2080s, while those in other regions would notably increase. Relatively dry climate in the south-central part might lead to an increased risk of drought. Precipitation in the east was higher than those of the other regions during the historical periods; nonetheless, it is projected to increase significantly in the future, leading to increased flooding risks.

In this research, VCED was developed for projecting monthly precipitation under climate change. Further extensions to daily-scale projections are desired. However, issues related to sample autocorrelation in daily precipitation series need to be addressed before the VCED-based downscaling can be undertaken. VCED can be extended to other climate variables, such as temperature and wind speed, and can also facilitate the downscaling of GCM projections. Among the copula functions that have passed the statistical tests in VCED modeling, those that are more sensitive to differences in correlation coefficients would have better performance in climate projections.

\section{Acknowledgements}

This research was supported by the Natural Sciences Foundation (51520105013, 51679087), the National Key Research and Development Plan (2016YFC0502800, 2016YFA0601502), the 111 Program (B14008) and the Natural Science and Engineering Research Council of Canada, the Fundamental Research Funds for the Central Universities (2016XS89). The observed precipitation data are available at the National Meteorological Information Center (http://data.cma.cn/). The RCM simulation results from our research team are available at the Climate Change Data Portal (http://chinaccdp.org/). Other RCM data can be obtained from the CORDEX website (http://www.cordex.org). We are very grateful for L. Samaniego (the Associate Editor) and the anonymous reviewers' insightful and constructive comments. They are critically helpful for improving this manuscript.

\section{References}

Aas, K., Czado, C., Frigessi, A., \& Bakken, H. (2006). Pair-copula constructions of multiple dependence. Insurance Mathematics \& Economics, 44(2), 182-198. https://doi.org/10.1016/j.insmatheco.2007.02.001

Alidoost, F., Stein, A., Su, Z. (2019) The use of bivariate copulas for bias correction of reanalysis air temperature data. PLoS ONE, 14(5), e0216059. https://doi.org/10.1371/journal.pone.0216059

Anderson, J. L. (1996). A method for producing and evaluating probabilistic forecasts from ensemble model integrations. Journal of Climate, 9, 1518-1530.

https://doi.org/10.1175/1520-0442(1996)009<1518:AMFPAE>2.0.CO;2

This article is protected by copyright. All rights reserved. 
Boé, J. Terray, L., Habets, F., \& Martin, E. (2007). Statistical and dynamical downscaling of the seine basin climate for hydro-meteorological studies. International Journal of Climatology, 27(12), 1643-1655. https://doi.org/10.1002/joc.1602

Bowden, J. H., Otte, T. L., Nolte, C. G., \& Otte, M. J. (2012). Examining interior grid nudging techniques using two-way nesting in the wrf model for regional climate modeling. Journal of Climate, 25(8), 2805-2823. https://doi.org/10.1175/JCLI-D-11-00167.1

Brechmann, E. C., \& Schepsmeier, U. (2013). Modeling dependence with C- and D-vine copulas: the R package CDvine. Journal of Statistical Software, 052. https://doi.org/10.18637/jss.v052.i03

Buytaert, W., Vuille, M., Dewulf, A., Urrutia, R., Karmalkar, A., \& Célleri, R. (2010). Uncertainties in climate change projections and regional downscaling in the tropical andes: implications for water resources management. Hydrology and Earth System Sciences, 14(7), 1247-1258. https://doi.org/10.5194/hess-14-1247-2010

Chen, J., Brissette, F. P., Chaumont, D., \& Braun, M. (2013). Finding appropriate bias correction methods in downscaling precipitation for hydrologic impact studies over North America. Water Resources Research, 49(7), 4187-4205. https://doi.org/10.1002/wrcr.20331

Clark, M., Gangopadhyay, S., Hay, L., Rajagopalan, B., \& Wilby, R. (2004). The schaake shuffle: a method for reconstructing space-time variability in forecasted precipitation and temperature fields. Journal of Hydrometeorology, 5(1), 243. https://doi.org/10.1175/1525-7541(2004)005<0243:TSSAMF>2.0.CO;2

CORDEX (Coordinated Regional Downscaling Experiment), https://cordex.org/data-access/biasadjusted-rcm-data/

Deser, C., Phillips, A., Bourdette, V., \& Teng, H. (2012). Uncertainty in climate change projections: the role of internal variability. Climate Dynamics, 38(3-4), 527-546. https://doi.org/10.1007/s00382-010-0977-x

Di Virgilio, G., Evans, J. P., Di Luca, A., Olson, R., Argüeso, Daniel, \& Kala, J., et al. (2019). Evaluating reanalysis-driven CORDEX regional climate models over Australia: model performance and errors. Climate Dynamics, 53, 2985-3005. https://doi.org/10.1007/s00382-019-04672-w

Diallo, I., Bain, C.L., Gaye, A.T., \& Wilfran Moufouma-Okia. (2014). Simulation of the West African monsoon onset using the HadGEM3-RA regional climate model. Climate Dynamics, 43(3-4), 575-594. https://doi.org/10.1007/s00382-014-2219-0

D'Oria, M., Ferraresi, M., \& Tanda, M. G. (2017). Historical trends and high-resolution future climate projections in Northern Tuscany (Italy). Journal of Hydrology, 555. https://doi.org/10.1016/j.jhydrol.2017.10.054

This article is protected by copyright. All rights reserved. 
Dosio, A., \& Paruolo, P. (2012). Bias correction of the ensembles high-resolution climate change projections for use by impact models: evaluation on the present climate. Journal of Geophysical Research: Atmospheres, 117(D17) https://doi.org/10.1029/2012JD017968

Engen-Skaugen, T. (2007). Refinement of dynamically downscaled precipitation and temperature scenarios. Climatic Change, 84(3-4), 365-382. https://doi.org/10.1007/s10584-007-9251-6

Fan, Y. R., Huang, W. W., Huang, G. H., Huang, K., Li, Y. P., \& Kong, X. M. (2015). Bivariate hydrologic risk analysis based on a coupled entropy-copula method for the Xiangxi River in the Three Gorges reservoir area, China. Theoretical \& Applied Climatology, 125(1-2), 381-397. https://doi.org/10.1007/s00704-015-1505-z

Frei, C., Christensen, J. H., Déqué, M., Jacob, D., Jones, R. G., \& Vidale, P. L. (2003). Daily precipitation statistics in regional climate models: evaluation and intercomparison for the European Alps. Journal of Geophysical Research: Atmospheres, 108(D3), 1-9. https://doi.org/10.1029/2002JD002287

Gao, X., Zhao, Q., Zhao, X., Wu, P., Pan, W., \& Gao, X., et al. (2017). Temporal and spatial evolution of the Standardized Precipitation Evapotranspiration Index (SPEI) in the Loess Plateau under climate change from 2001 to 2050. Science of the Total Environment, 595, 191. https://doi.org/10.1016/j.scitotenv.2017.03.226

Gao, Z. L., Li, Y. H., Xu, J., Wang, Z. Z., Zhao, J., Guo, W., et al. (2009). Research on ecoconstruction and control measures of soil and water loss in the Loess Plateau (in Chinese). Science Technology and Industry, 9, 1-12.

Genest, C., Rémillard, B., \& Beaudoin, D. (2009). Goodness-of-fit tests for copulas: a review and a power study. Insurance Mathematics \& Economics, 44(2), 199-213. https://doi.org/10.1016/j.insmatheco.2007.10.005

Giorgi, F., Jones, C., \& Asrar, G. R. (2009). Addressing climate information needs at the regional level: the CORDEX framework. Bulletin - World Meteorological Organization, 58(3), 175-183.

Gudmundsson, L., Bremnes, J. B., Haugen, J. E., \& Engenskaugen, T. (2012). Technical note: downscaling RCM precipitation to the station scale using statistical transformations - a comparison of methods. Hydrology \& Earth System Sciences Discussions, 9(5), 61856201. https://doi.org/10.5194/hessd-9-6185-2012

Hamill, T.M. (2001). Interpretation of rank histograms for verifying ensemble forecasts. Monthly Weather Review, 129(3), 550. https://doi.org/10.1175/15200493(2001)129<0550:IORHFV>2.0.CO;2

Harding, K. J., \& Snyder, P. K. (2014). Examining future changes in the character of central U.S. warm-season precipitation using dynamical downscaling. Journal of Geophysical Research: Atmospheres, 119(23), 13,116-13,136. https://doi.org/10.1002/2014JD022575

This article is protected by copyright. All rights reserved. 
Hou, Y. K., He, Y. F., Chen, H., Xu, C.Y., Chen, J., \& Kim, J.S., et al. (2019). Comparison of multiple downscaling techniques for climate change projections given the different climatic zones in China. Theoretical and Applied Climatology, 138, $27-45$. https://doi.org/10.1007/s00704-019-02794-z

Hu, X. M., Xue, M., Mcpherson, R. A., Martin, E., Rosendahl, D. H., \& Qiao, L. (2018). Precipitation dynamical downscaling over the great plains. Journal of Advances in Modeling Earth Systems, 10(2), 421-447. https://doi.org/10.1002/2017MS001154

IPCC, (2015). Report of the Intergovernmental Panel on Climate Change Workshop on Regional Climate Projections and their Use in Impacts and Risk Analysis Studies. IPCC Working Group I Technical Support Unit, University of Bern, Bern, Switzerland.

Johnson, F., \& Sharma, A. (2011). Accounting for interannual variability: a comparison of options for water resources climate change impact assessments. Water Resources Research, 47(4). https://doi.org/10.1029/2010WR009272

Kong, X. M., Huang, G.H., Fan, Y.R., Li, Y.P. (2015). Maximum entropy-gumbel-hougaard copula method for simulation of monthly streamflow in Xiangxi River, China. Stochastic Environmental Research \& Risk Assessment, 29, 833-846. https://doi.org/10.1007/s00477-014-0978-0

Kupiainen, M., Jansson, C., Samuelsson, P., Jones, C., Wille'n, U. et al. 2014. Rossby Centre regional atmospheric model, RCA4, Rossby Center News Letter. Online at: http://www.smhi.se/en/Research/Research-departments/climate-research-rossby-centre2$552 / 1.16562$

Kurowicka, D., \& Joe, H. (2011) Dependence modeling: vine copula handbook. World Scientific, Singapore. https://doi.org/10.1142/7699

Lee, M. I., Schubert, S. D., Suarez, M. J., Held, I. M., Kumar, A., \& Bell, T. L., et al. (2007). Sensitivity to horizontal resolution in the AGCM simulations of warm season diurnal cycle of precipitation over the United States and northern Mexico. Journal of Climate, 20(9), 1862-1881. https://doi.org/10.1175/JCLI4090.1

Liang, W., Bai, D., Wang, F., Fu, B., Yan, J., \& Wang, S., et al. (2015). Quantifying the impacts of climate change and ecological restoration on streamflow changes based on a Budyko hydrological model in China's Loess Plateau. Water Resources Research, 51(8), 65006519. https://doi.org/10.1002/2014WR016589

Liang, X. Z., Pan, J., Zhu, J., Kunkel, K. E., Wang, J. X. L., \& Dai, A. (2006). Regional climate model downscaling of the U.S. summer climate and future change. Journal of Geophysical Research: Atmospheres, 111, D10108. https://doi.org/10.1029/2005JD006685

Li, Z., Zheng, F. L., \& Liu, W. Z. (2012). Spatiotemporal characteristics of reference evapotranspiration during 1961-2009 and its projected changes during 2011-2099 on the

This article is protected by copyright. All rights reserved. 
Loess Plateau of China. Agricultural \& Forest Meteorology, 154(6), 147-155. https://doi.org/10.1016/j.agrformet.2011.10.019

Liu, W., \& Sang, T. (2013). Potential productivity of the Miscanthus energy crop in the Loess Plateau of China under climate change. Environmental Research Letters, 8(4), 4003. https://doi.org/10.1088/1748-9326/8/4/044003

Mao, G., Vogl, S., Laux, P., Wagner, S., \& Kunstmann, H. (2015) Stochastic bias correction of dynamically downscaled precipitation fields for Germany through Copula-based integration of gridded observation data. Hydrology and Earth System Sciences. 19(4), 1787-806. https://doi.org/10.5194/hess-19-1787-2015

Maity, R., Suman, M., Laux, P., \& Kunstmann, H. (2019). Bias correction of zero-inflated RCM precipitation fields: a copula-based scheme for both mean and extreme conditions, Journal of Hydrometeorology, 4, 595-611. https://doi.org/10.1175/JHM-D-18-0126.1

Nelsen, R. B. (2006), An Introduction to Copulas, Springer, New York

Pal, J., Giorgi, F., Bi, X., Elguindi, N., Solmon, F., Gao, X. J., Rauscher, S. A., Francisco, R., \& Zakey, S., et al. (2007). Regional climate modeling for the developing world: the ITCP RegCM3 and RegCNET. Bulletin of the American Meteorological Society, 88(9), 13951409. https://doi.org/10.1175/BAMS-88-9-1395

Piani, C., Haerter, J. O., \& Coppola, E. (2010a). Statistical bias correction for daily precipitation in regional climate models over Europe. Theoretical \& Applied Climatology, 99(1-2), 187-192. https://doi.org/10.1007/s00704-009-0134-9

Piani, C., Weedon, G. P., Best, M., Gomes, S. M., Viterbo, P., \& Hagemann, S., et al. (2010b). Statistical bias correction of global simulated daily precipitation and temperature for the application of hydrological models. Journal of Hydrology, 395(3), 199-215. https://doi.org/10.1016/j.jhydrol.2010.10.024

Rosenblatt, M. (1952). Remarks on a multivariate transformation. Annals of Mathematical Statistics, 23(3), 470-472. https://doi.org/10.1214/aoms/1177729394

Samaniego, L., András Bárdossy, \& Kumar, R. (2010). Streamflow prediction in ungauged catchments using copula-based dissimilarity measures. Water Resources Research, 46. https://doi.org/10.1029/2008WR007695

Serinaldi, F. (2009), A multisite daily rainfall generator driven by bivariate copula-based mixed distributions, Journal of Geophysical Research, 114, D10103. https://doi.org/10.1029/2008JD011258

Shih, J. H., \& Louis, T. A. (1995). Inferences on the association parameter in copula models for bivariate survival data. Biometrics, 51(4), 1384-1399. https://doi.org/10.2307/2533269

Sklar, M. (1959). Fonctions de repartition à n dimensions et leurs marges. Publications de l'Institut de Statistique de l'Universite dé Paris, 8, 229-231. https://zbmath.org/0100.14202?

This article is protected by copyright. All rights reserved. 
Taylor, K. E. (2001). Summarizing multiple aspects of model performance in a single diagram. Journal of Geophysical Research, 106(D7), 7183. https://doi.org/10.1029/2000JD900719

Tebaldi, C., \& Knutti, R. (2007). The use of the multi-model ensemble in probabilistic climate projections. Philosophical Transactions of the Royal Society A: Mathematical, Physical and Engineering Sciences, 365(1857), 2053-2075. https://doi.org/10.1098/rsta.2007.2076

Teutschbein, C., \& Seibert, J. (2012). Bias correction of regional climate model simulations for hydrological climate-change impact studies: review and evaluation of different methods. Journal of Hydrology, 16, 12-29. https://doi.org/10.1016/j.jhydrol.2012.05.052

Themeß1, M. J., Gobiet, A., \& Heinrich, G. (2011). Empirical-statistical downscaling and error correction of regional climate models and its impact on the climate change signal. Climatic Change, 112(2), 449-468. https://doi.org/10.1007/s10584-011-0224-4

Thober, S., Mai, J. , Zink, M., \& Samaniego, L. (2014). Stochastic temporal disaggregation of monthly precipitation for regional gridded data sets. Water Resources Research, 50(11), 8714-8735. https://doi.org/10.1002/2014WR015930

Thober, S., \& Samaniego L. (2014), Robust ensemble selection by multivariate evaluation of extreme precipitation and temperature characteristics, Journal of Geophysical Research: Atmospheres, 119(2), 594-613. https://doi.org/10.1002/2013JD020505

Thober, S., Samaniego, L., \& Bardossy, A. (2013). Large-Scale Weather Generator for Downscaling Precipitation. Egu General Assembly Conference.

Thober, S., Samaniego, L., \& Kumar, R. (2012). Evaluation of Regional Climate Models: Extremes important for Hydrological Projections. Egu General Assembly Conference.

Torma, C., Giorgi, F., \& Coppola, E. (2015). Added value of regional climate modeling over areas characterized by complex terrain-precipitation over the Alps. Journal of Geophysical Research: Atmospheres, 120(9), 3957-3972. https://doi.org/10.1002/2014JD022781

Vogl, S., Laux, P., Qiu, W., Mao, G., \& Kunstmann, H. (2012). Copula-based assimilation of radar and gauge information to derive bias-corrected precipitation fields. Hydrology and Earth System Sciences. 16(7), 2311-2328. https://doi.org/10.5194/hess-16-2311-2012

Wang, L., \& Chen, W. (2014). A CMIP5 multimodel projection of future temperature, precipitation, and climatological drought in China. International Journal of Climatology, 34(6), 2059-2078. https://doi.org/10.1002/joc.3822

Wang, L., Cheung, K. K. W., Tam, C., Tai, A. P. K., \& Li, Y. (2017a). Evaluation of the regional climate model over the Loess Plateau of China. International Journal of Climatology, 38(1), 35-54. https://doi.org/10.1002/joc.5159

Wang, S., Fu, B., Piao, S., Lü, Y., Ciais, P., \& Feng, X., et al. (2017b). Reduced sediment transport in the Yellow River due to anthropogenic changes. Nature Geoscience, 9(1), 38-41. https://doi.org/10.1038/ngeo2602

This article is protected by copyright. All rights reserved. 
Wang, X., Huang, G., \& Liu, J. (2014). Projected increases in intensity and frequency of rainfall extremes through a regional climate modeling approach. Journal of Geophysical Research: Atmospheres, 119(23), 271-286. https://doi.org/10.1002/2014JD022564

Wei, Q., \& Liu, J. (2018). A non-stationary cost-benefit based bivariate extreme flood estimation approach. Journal of Hydrology, 557, 589-599. https://doi.org/10.1016/j.jhydrol.2017.12.045

Zhang, B., Wu, P., Zhao, X., Wang, Y., Wang, J., \& Shi, Y. (2012). Drought variation trends in different subregions of the Chinese Loess Plateau over the past four decades. Agricultural Water Management, 115, 167-177. https://doi.org/10.1016/j.agwat.2012.09.004

Zhou, X., Huang, G., Wang, X., Fan, Y., \& Cheng, G. (2018). A coupled dynamical-copula downscaling approach for temperature projections over the Canadian Prairies. Climate Dynamics, 51, 2413-2431. https://doi.org/10.1007/s00382-017-4020-3

This article is protected by copyright. All rights reserved. 


\section{Captions of Tables}

Table 1. Regional climate models (RCMs) together with the driving global climate models (GCMs).

Table 2. The 21 numbered combinations of 7 RCMs (the number of individual RCMs are shown in Table 1).

Table 3. Comparison of MAE of observations and bias-corrected simulations for monthly mean precipitation.

\section{Captions of Figures}

Figure 1. Location and topography map of the Loess Plateau, with 44 meteorological stations indicated.

Figure 2. Structure of the vine copula model and parameters with different $\tau$ values between decomposed pair-copulas.

Figure 3. Illustration of the Rosenblatt transform and its inverse calculation, where (a) shows the correlation between $\boldsymbol{u}_{2}$ and $\boldsymbol{u}_{3}$, (b) indicates the correlation between $\boldsymbol{w}_{2}$ and $\boldsymbol{w}_{3}$, (c) shows the probabilistic distribution of 300 samples for $w_{3, i}$, (d) gives the probabilistic distribution of the variable to be bias-corrected (i.e. $u_{3, i}$ ), and (e) shows the simulation results for the entire $\boldsymbol{u}_{3}$ (averaged $u_{3, i}$ ) sequence.

Figure 4. Monthly mean precipitation from PRECIS and RegCM datasets before postdownscaling analyses at nine meteorological stations during the validation period (1996-2004).

Figure 5. Post-downscaling results using different methods for monthly mean precipitation at nine meteorological stations during the validation period (1996-2004).

Figure 6. Comparisons between different methods. Left: comparison of monthly mean precipitation at all stations. Right: average MAE for all stations and at each probability interval.

Figure 7. Taylor diagram (a), enlarged diagram (b), and ranking chart (c) for 35 schemes of verification (1996-2004). Red points derive from the Qmap method, blue points from the BiCopula method, and green points from VCED; ranking numbers are placed at the tops of the bars.

Figure 8. Ranking histograms for ensemble precipitation projections at 44 stations. Dashed line denotes an identical probability level; horizontal axes show 21 ensemble members with 22 bins.

This article is protected by copyright. All rights reserved. 
Figure 9. Monthly mean interval (shadowed) of precipitation during the verification stage (1996-2004) obtained from 21 groups of downscaling results at 44 stations. Black lines represent monthly mean observations; red lines represent the ensemble mean predictions.

Figure 10. Comparison between the historical average annual precipitation and projected mean ensemble precipitation under two RCP scenarios in which (a) denotes the historical average annual precipitation, (b) represents the mean ensemble precipitation during the 2050s under RCP 4.5, (c) the 2050s under RCP 8.5, (d) the 2080s under RCP 4.5, and (e) the 2080s under RCP 8.5.

Figure 11. Comparison of average annual precipitation in the rainy season between historical observations and two RCP scenarios in which (a) shows observations, (b) shows the mean ensemble of RCP 4.5 for the 2050s, (c) denotes the mean ensemble of RCP 4.5 for the 2080s, (d) shows the mean ensemble of RCP 8.5 for the 2050s, (e) represents the mean ensemble of RCP 8.5 for the 2080s, (f-i) represent future lower-limit ensembles corresponding to (b-e), and (j-m) are future upper-limit ensembles corresponding to (b-e).

Figure 12. Projected changes of the rainy season at 44 stations on the Loess Plateau between two 30-year periods under two RCP scenarios, compared with the historical period.

This article is protected by copyright. All rights reserved. 
Table 1 Regional climate models (RCMs) together with the driving global climate models (GCMs).

\begin{tabular}{|c|c|c|c|c|c|c|c|}
\hline Number & (1) & (2) & (3) & (4) & (5) & (6) & (7) \\
\hline GCMs & \multicolumn{2}{|c|}{ HadGEM-ES } & \multicolumn{2}{|c|}{ GFDL-ESM2M } & IPSL-CM5A-MR & MPI-ESM-LR & HadGEM2-AO \\
\hline RCMs & PRECIS & $\mathrm{RegCM}$ & RegCM & RCA4 & $\mathrm{RCA}^{1}{ }^{1}$ & RCA4 & HadGEM3-RA ${ }^{2}$ \\
\hline Institution & Uni & sity of R & sina & SMHI & SMHI & SMHI & NIMR \\
\hline
\end{tabular}

${ }^{\prime}:$ Rossby Centre regional climate model, Detailed information can be obtained through Kupiainen et al., 2014

${ }^{2}$ : Detailed introduction about the HadGEM3-RA regional climate models is shown in Diallo et al., 2014.

SMHI: Swedish Meteorological and Hydrological Institute

NIMR: National Institute of Meteorological Research, KMA, South Korea

Table 2 The 21 numbered combinations of 7 RCMs (the number of individual RCMs are shown in Table 1).

\begin{tabular}{ccccccc}
\hline RCMs & $(1)$ & $(2)$ & $(3)$ & $(4)$ & (5) & $(6)$ \\
\hline$(2)$ & 1 & & & & & \\
$(3)$ & 2 & 7 & & & & \\
$(4)$ & 3 & 8 & 12 & & & \\
$(5)$ & 4 & 9 & 13 & 16 & 19 & \\
$(6)$ & 5 & 10 & 14 & 17 & 20 & 21 \\
$(7)$ & 6 & 11 & 15 & 18 & 20 \\
\hline
\end{tabular}

Table 3 Comparison of MAE of observations and bias-corrected simulations for monthly mean precipitation.

\begin{tabular}{|c|c|c|c|c|c|c|c|c|c|c|c|}
\hline \multicolumn{2}{|c|}{ Scheme } & \multicolumn{9}{|c|}{ Station number } & \multirow[t]{2}{*}{ Mean } \\
\hline & & 1 & 2 & 3 & 4 & 5 & 6 & 7 & 8 & 9 & \\
\hline \multicolumn{2}{|c|}{ VCED } & 6.67 & 4.02 & 7.17 & 6.51 & 12.37 & 6.5 & 6.64 & 9.59 & 6.4 & 7.32 \\
\hline \multirow[t]{2}{*}{ Qmap } & PRECIS & 14.31 & 8.36 & 8.68 & 7.39 & 22.84 & 14.83 & 16.09 & 18.94 & 15.8 & 14.14 \\
\hline & RegCM & 10.09 & 3.68 & 8.7 & 6.2 & 13.17 & 11.49 & 12.02 & 10.95 & 16.99 & 10.37 \\
\hline \multirow[t]{2}{*}{ Bi-Copula } & PRECIS & 11.87 & 5.97 & 8.56 & 6.71 & 13.9 & 10.31 & 13.02 & 17.56 & 13.51 & 11.27 \\
\hline & $\operatorname{RegCM}$ & 8.43 & 4.63 & 11.2 & 6.45 & 10.29 & 8.95 & 8.66 & 11.22 & 7.25 & 8.56 \\
\hline
\end{tabular}

This article is protected by copyright. All rights reserved. 


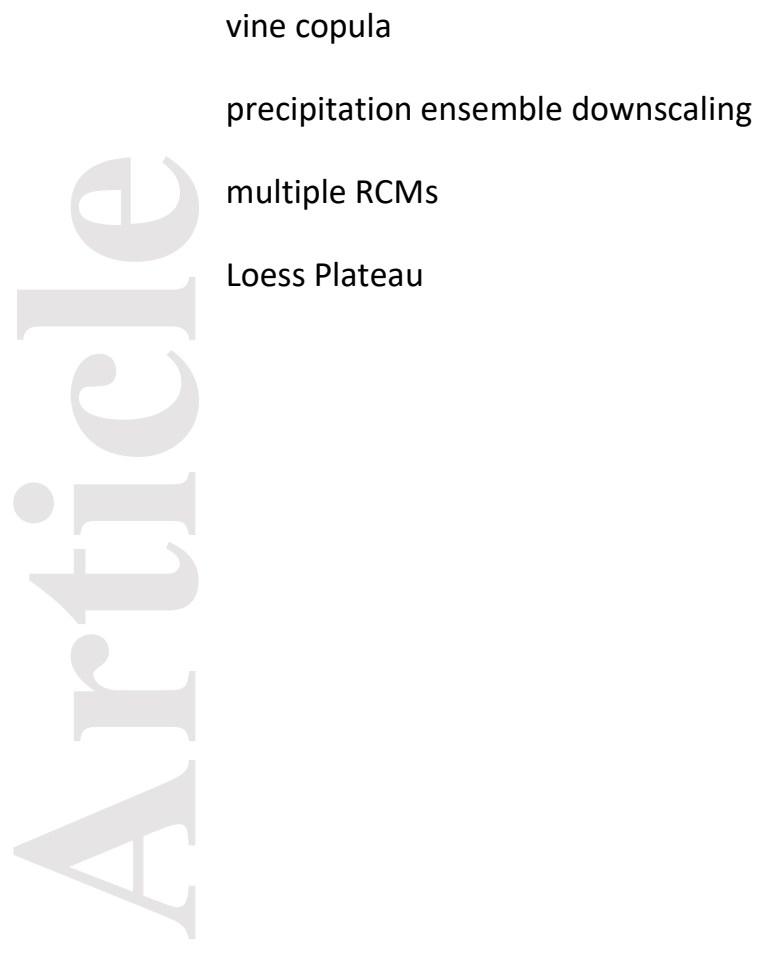

This article is protected by copyright. All rights reserved. 

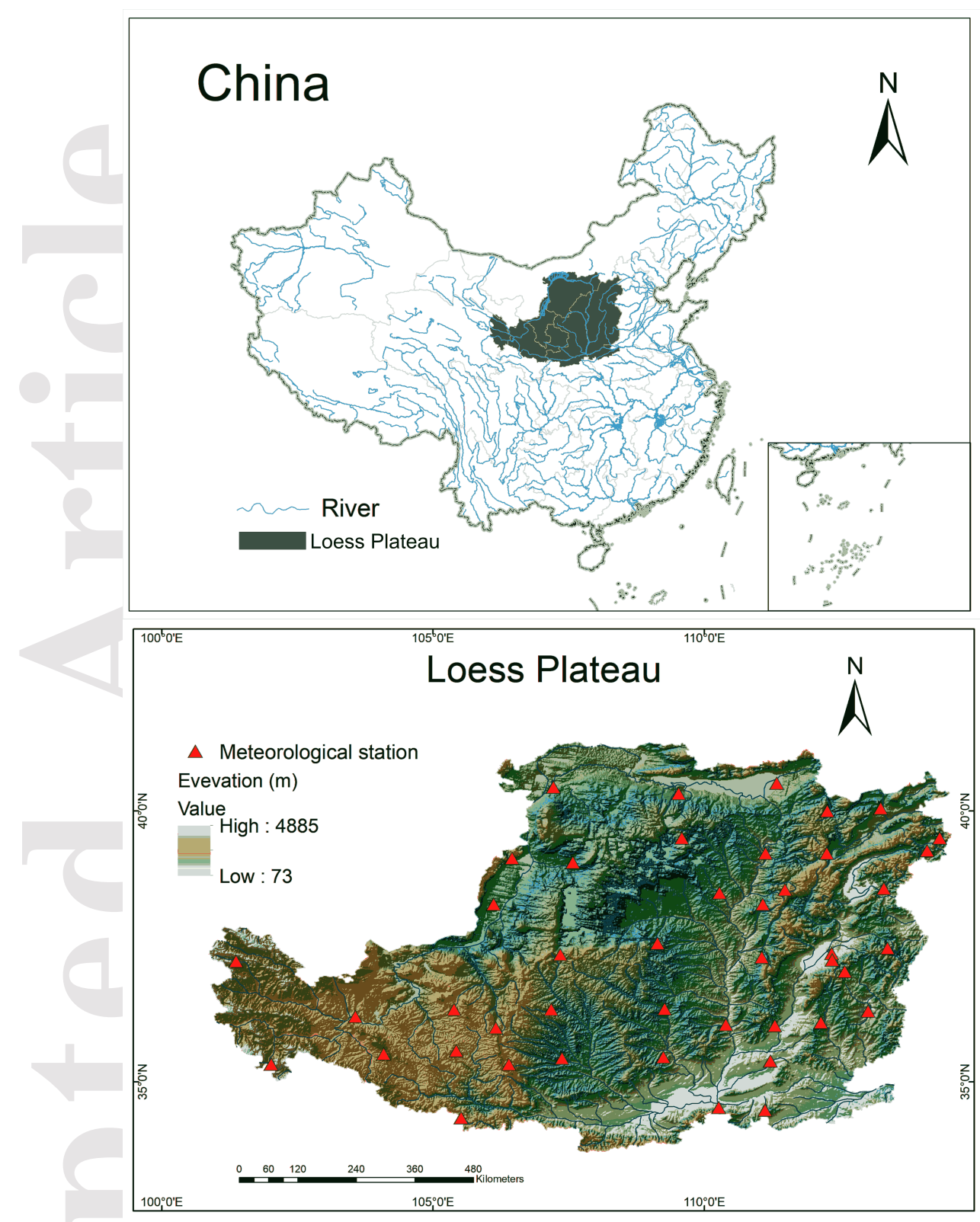

This article is protected by copyright. All rights reserved. 
(a)

$$
\theta 1=11
$$

$\theta 2=10$

Tree 1
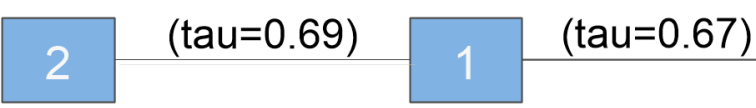

3

Tree 2

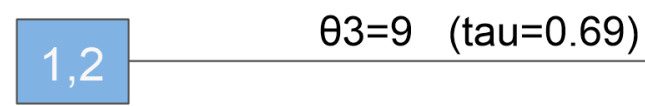

1,3

(b)

$$
\begin{gathered}
F_{2}\left(x_{2}\right)-\mathrm{C}_{1,2}-F_{1}\left(x_{1}\right)-\mathrm{C}_{1,3}-F_{3}\left(x_{3}\right) \\
F_{2 \mid 1}\left(x_{2} \mid x_{1}\right)-\mathrm{c}_{2,3 \mid 1}-F_{3 \mid 1}\left(x_{3} \mid x_{1}\right) \\
F_{3 \mid 1,2}\left(x_{3} \mid x_{1}, x_{2}\right)
\end{gathered}
$$

This article is protected by copyright. All rights reserved. 

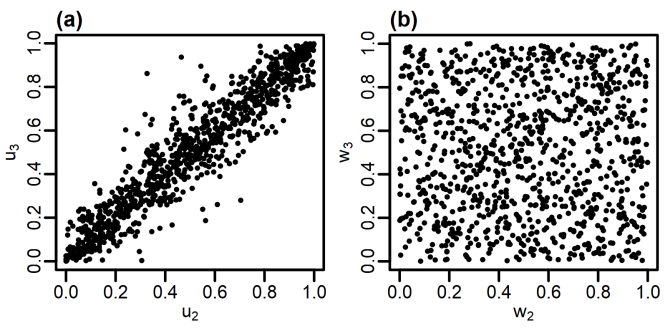

(c) $\quad \mathrm{w}_{3}$

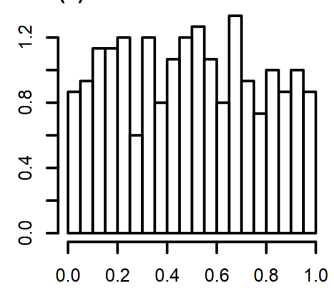

(d)

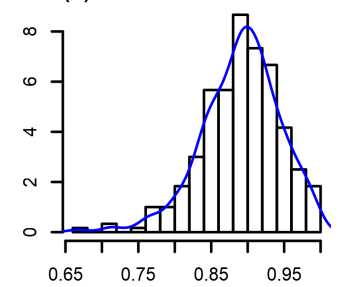

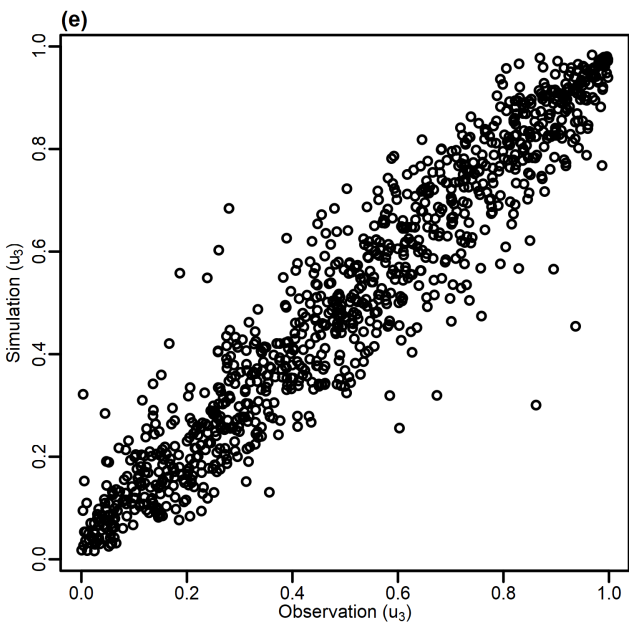

This article is protected by copyright. All rights reserved. 

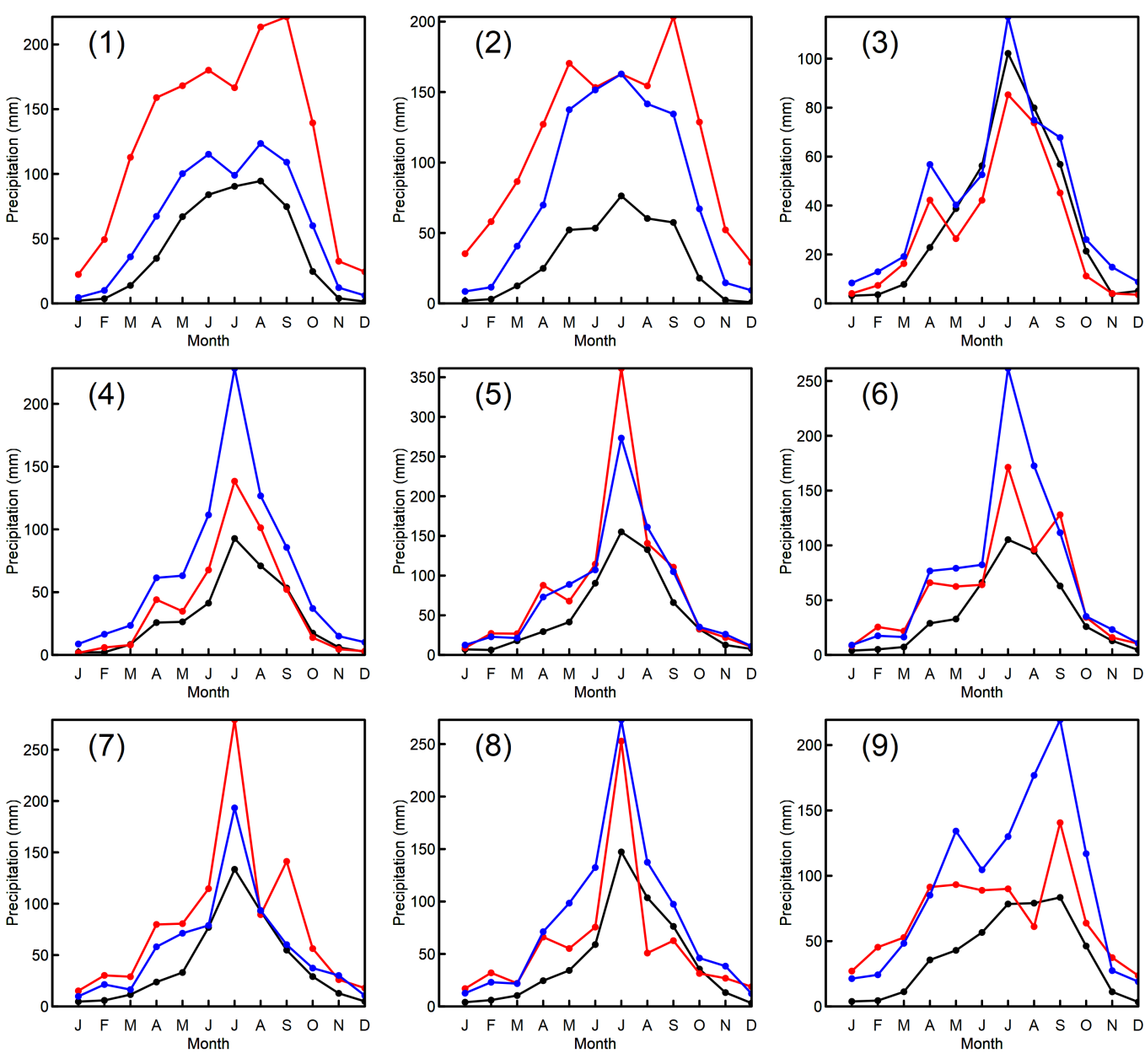

— Observation (1996-2004)

$\longrightarrow$ PRECIS (1996-2004) $\quad \longrightarrow$ RegCM (1996-2004)

This article is protected by copyright. All rights reserved. 

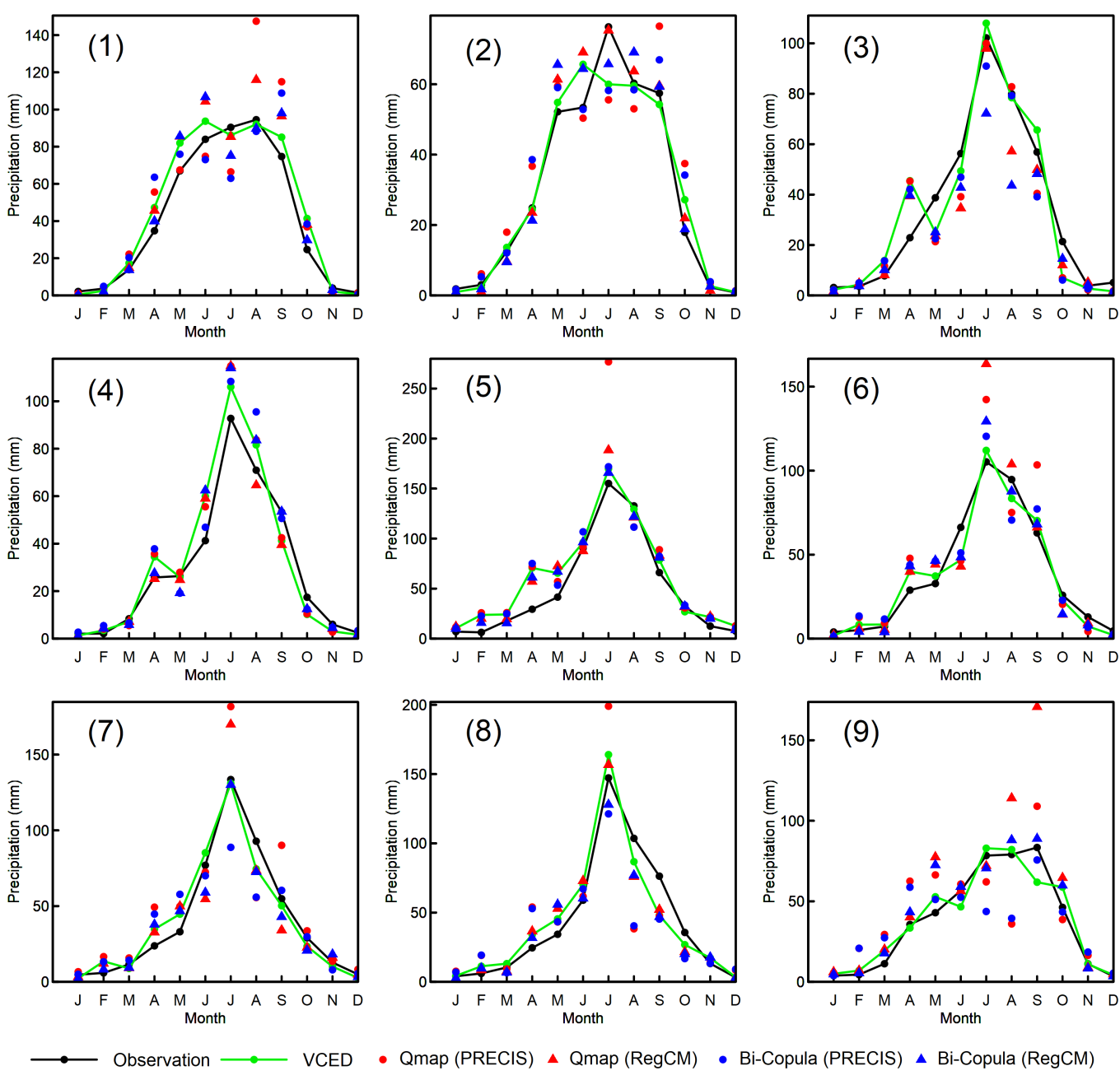

- Qmap (PRECIS) \ Qmap (RegCM) - Bi-Copula (PRECIS) \ Bi-Copula (RegCM)

This article is protected by copyright. All rights reserved. 

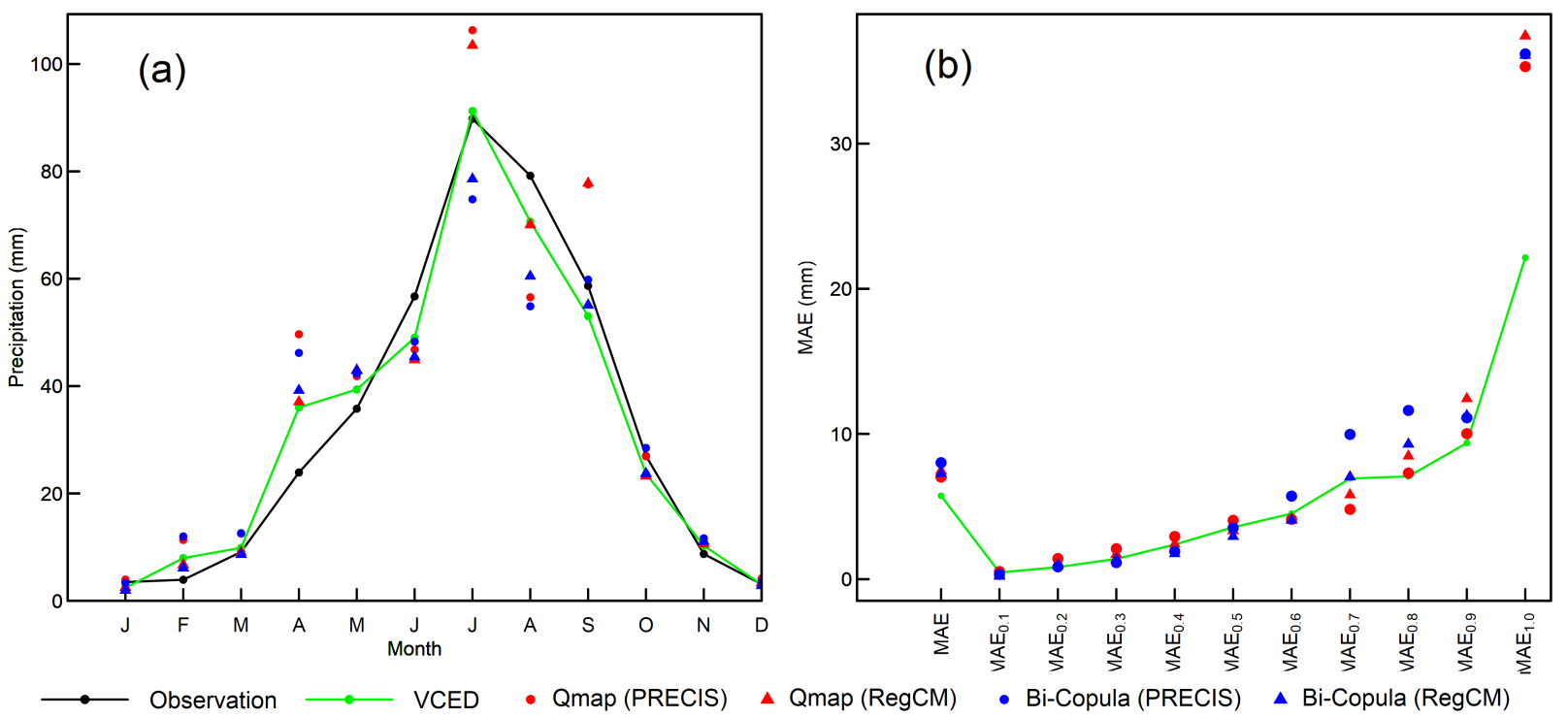

This article is protected by copyright. All rights reserved. 
(a)

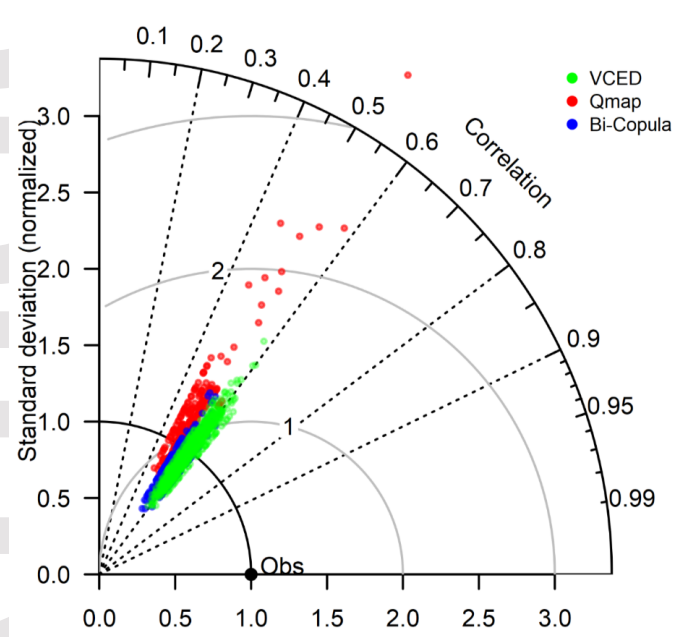

(b)

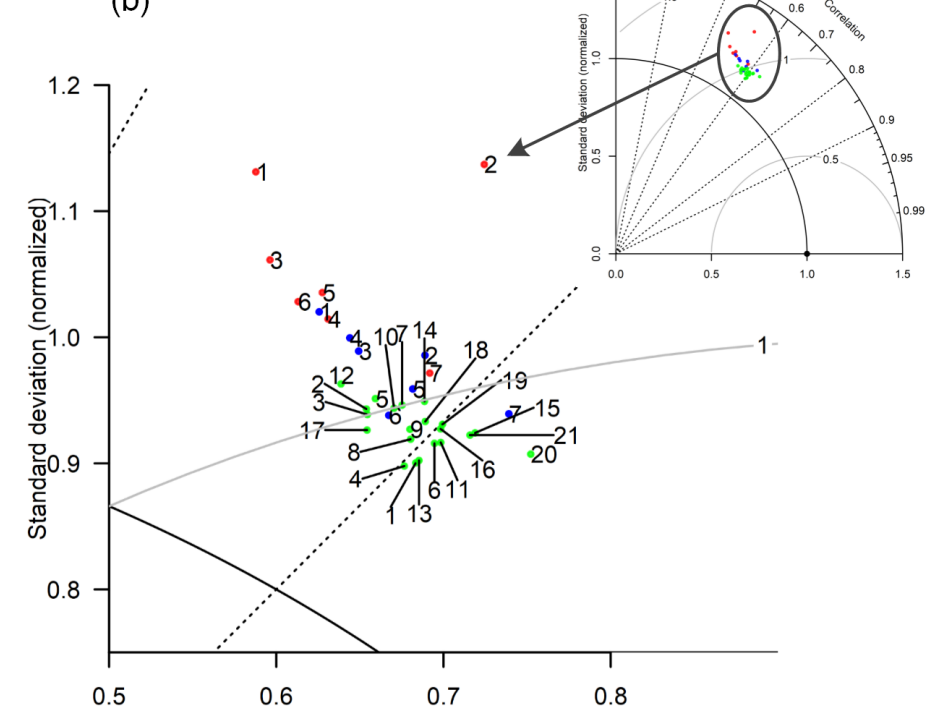

(c)

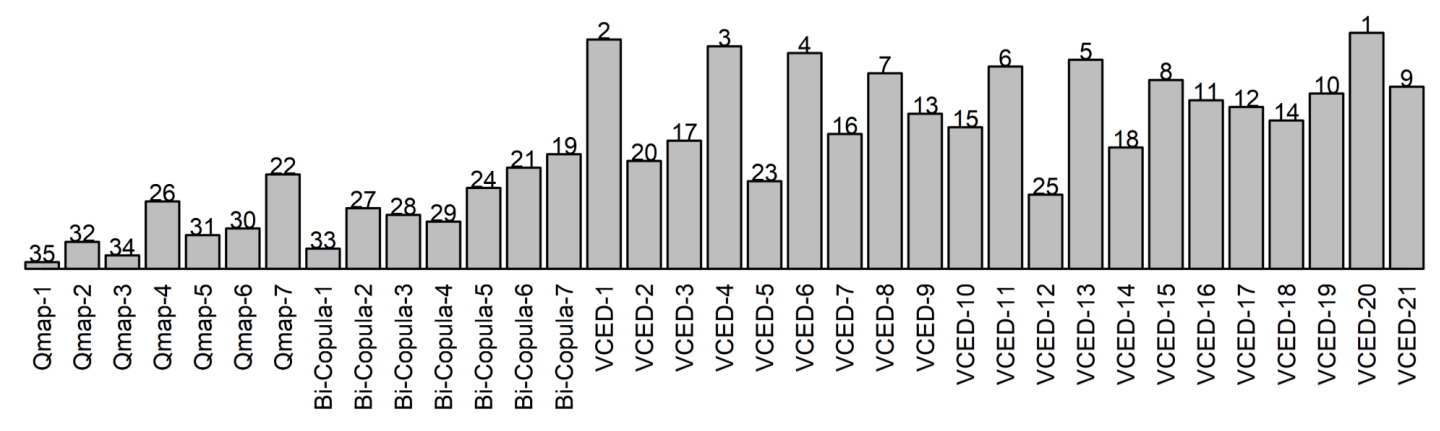

This article is protected by copyright. All rights reserved. 


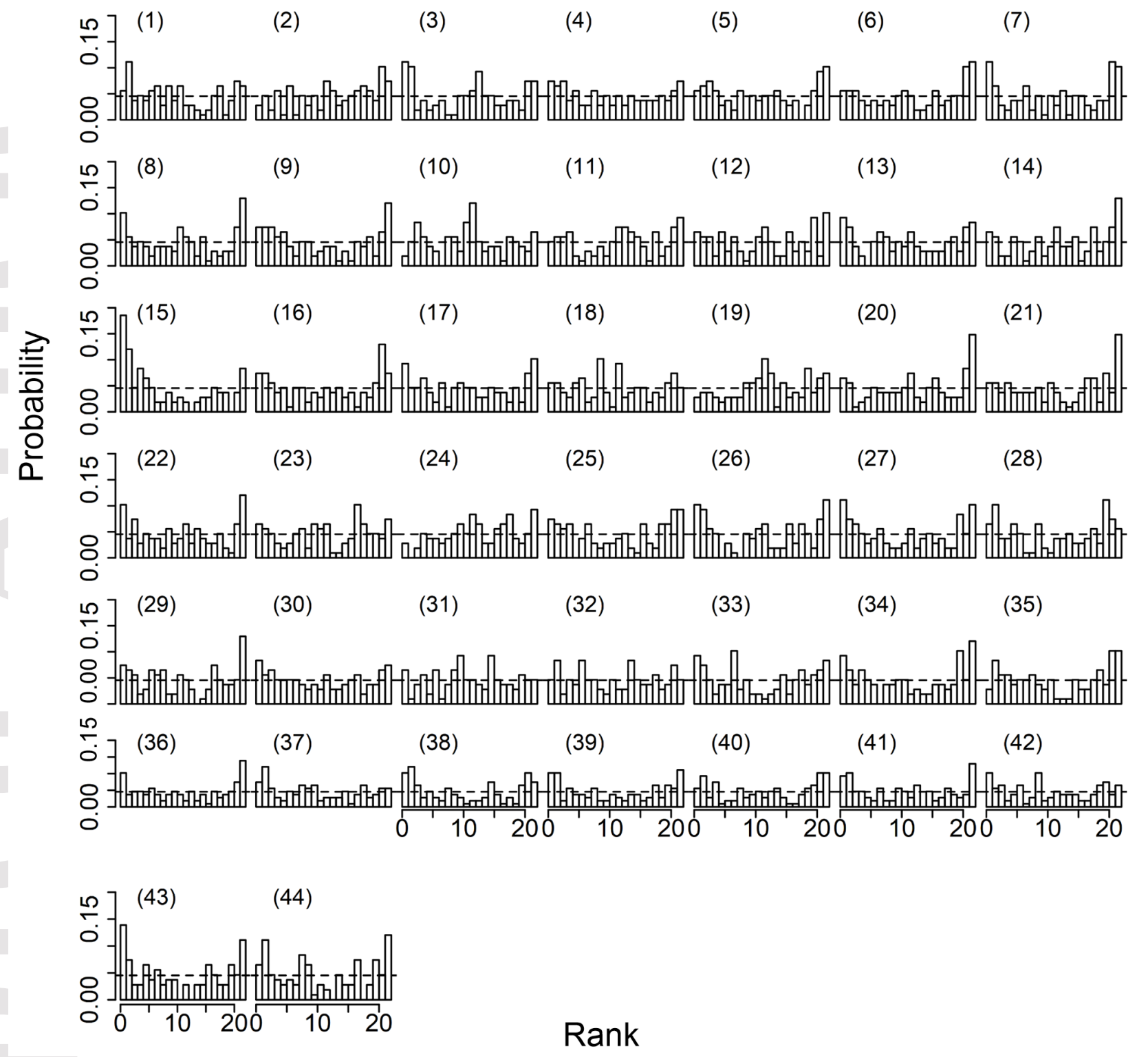

This article is protected by copyright. All rights reserved. 


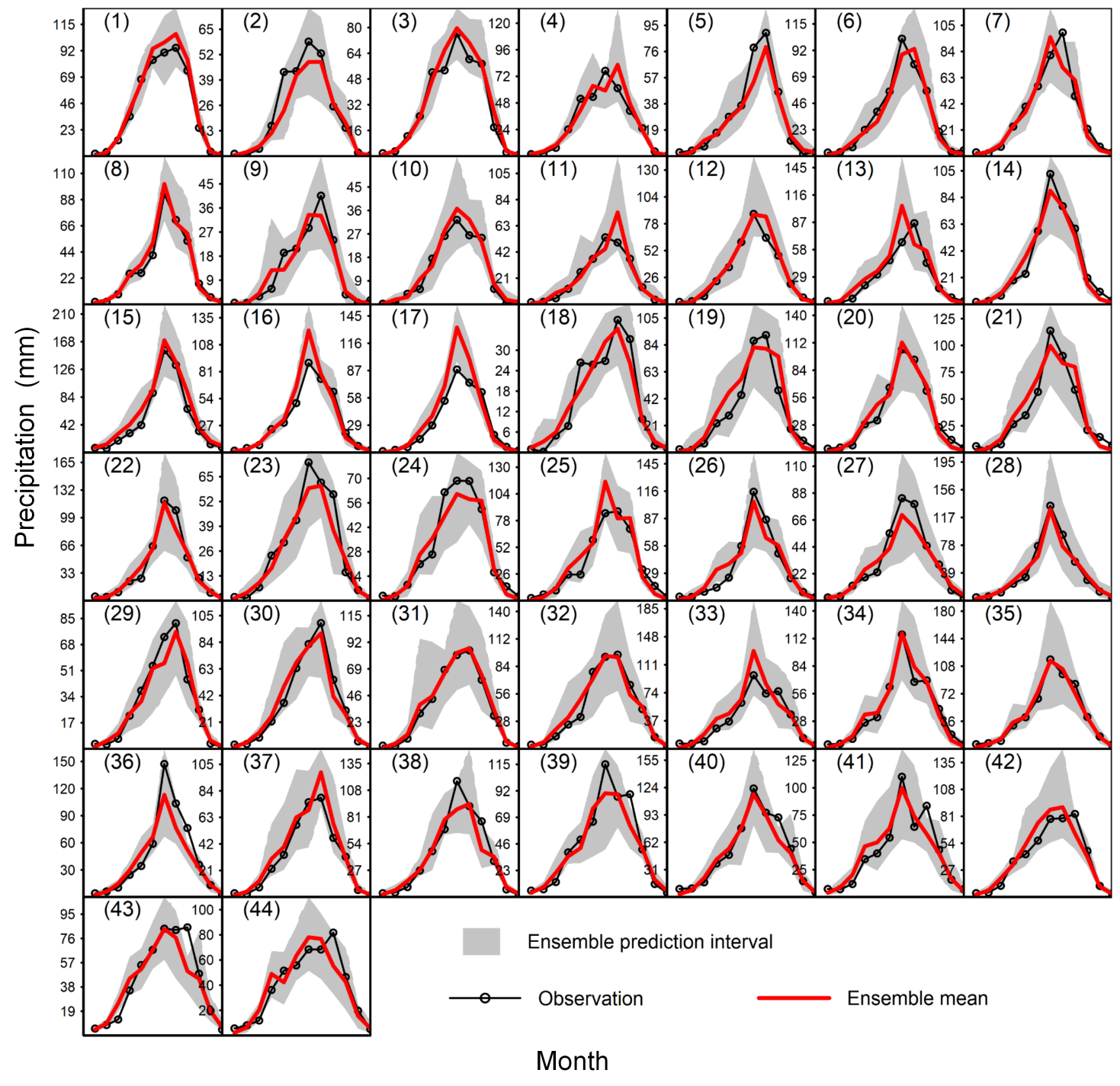

This article is protected by copyright. All rights reserved. 

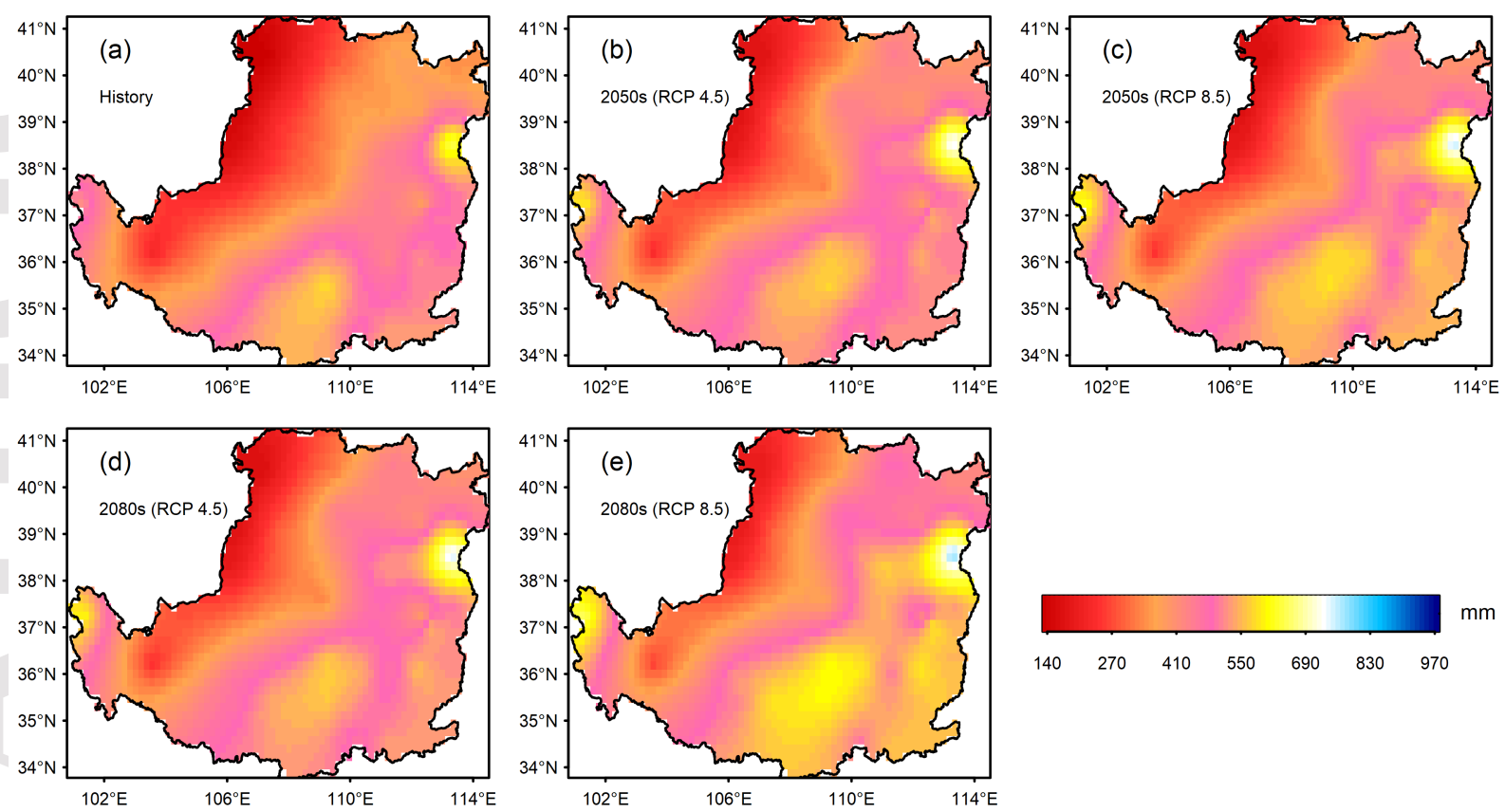

$\begin{array}{lllllll}140 & 270 & 410 & 550 & 690 & 830 & 970\end{array}$

This article is protected by copyright. All rights reserved. 

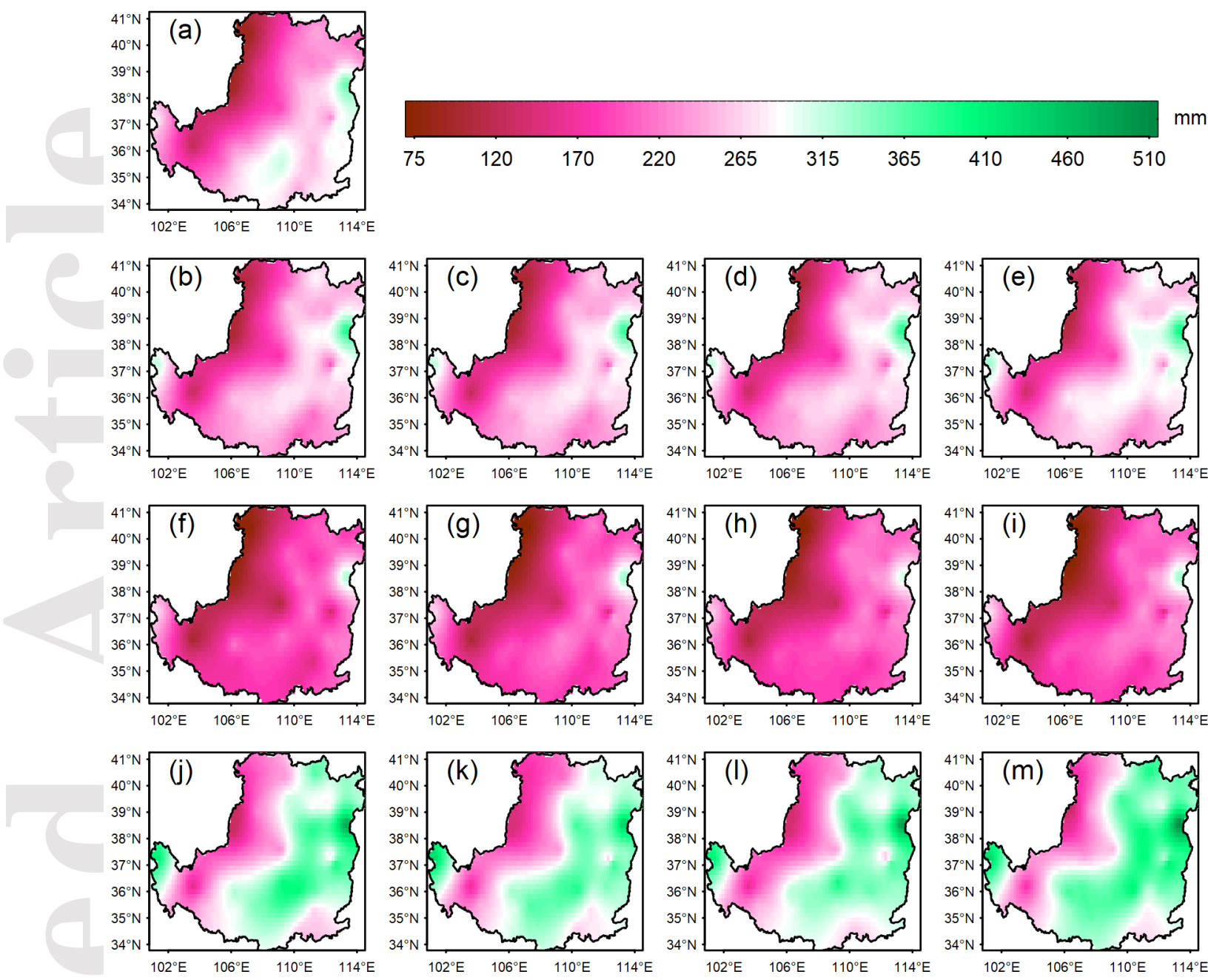

This article is protected by copyright. All rights reserved. 


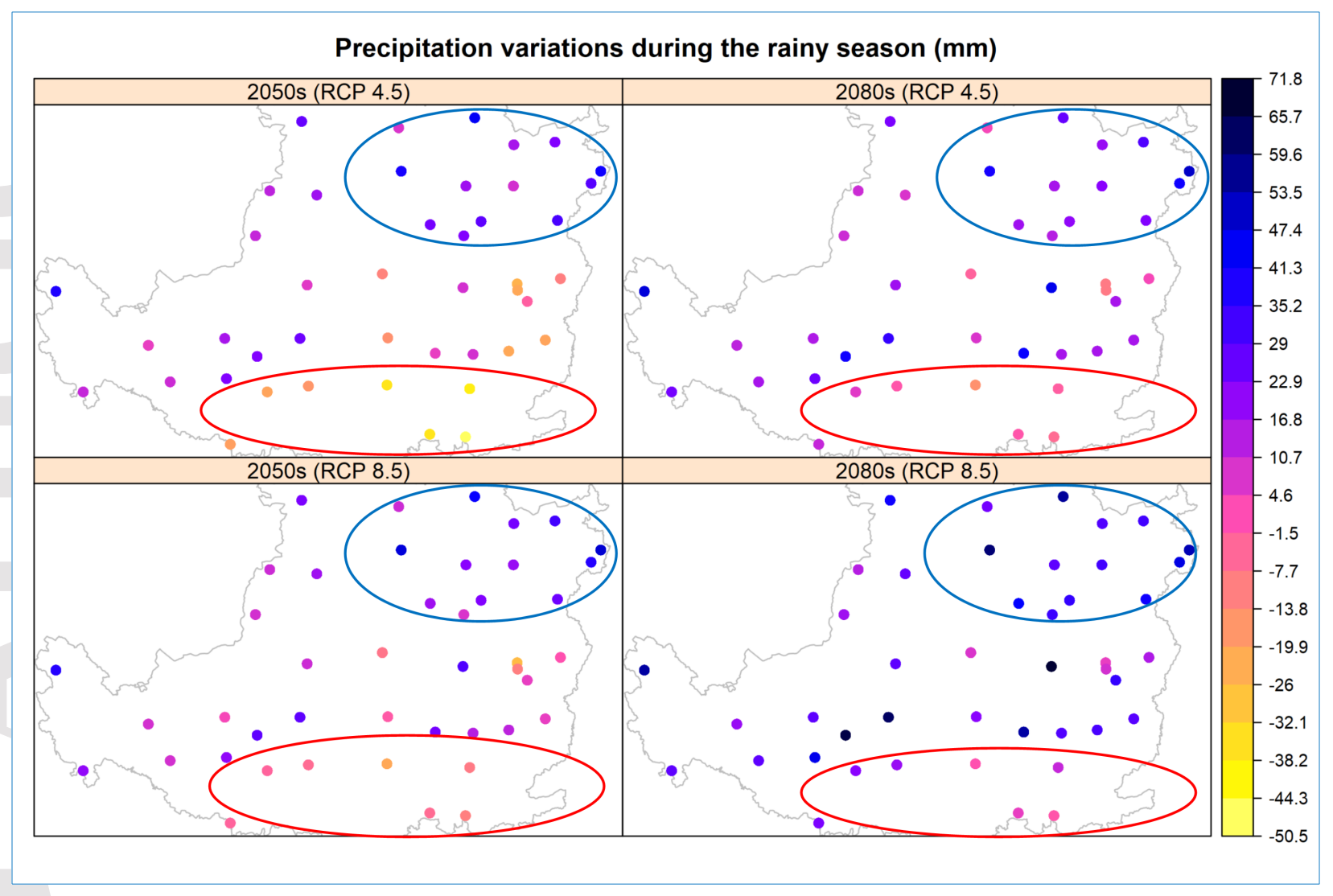

This article is protected by copyright. All rights reserved. 